\begin{abstract}
HHS Public Access
Author manuscript

J Hum Cap. Author manuscript; available in PMC 2019 August 21.

Published in final edited form as:

J Hum Cap. 2019 ; 13(2): 341-373. doi:10.1086/703160.

\section{Age and the Trying Out of New Ideas}

\author{
Mikko Packalen, \\ University of Waterloo; Department of Economics, 200 University Avenue West, ON N2L 3G1, \\ Canada; +1 (519) 8884567 \\ Jay Bhattacharya* \\ Stanford University School of Medicine; CHP/PCOR, Stanford University, 117 Encina Commons, \\ Stanford, CA 94305-6019 \\ Mikko Packalen: packalen@uwaterloo.ca; Jay Bhattacharya: jay@stanford.edu
}

\section{Abstract}

The aging of the scientific workforce and graying of grant recipients are central policy concerns in biomedicine. These trends are potentially important because older scientists are often seen as less open to new ideas than younger scientists. In this paper, we put this hypothesis to an empirical test. Using a measure of new ideas derived from the text of nearly all biomedical scientific articles published since 1946, we compare the tendency of younger and older researchers to try out new ideas in their work. We find that papers published in biomedicine by younger researchers are more likely to build on new ideas. Collaboration with an experienced researcher matters as well. Papers with a young first author and a more experienced last author are more likely to try out newer ideas than papers published by other team configurations. Given the crucial role that the trying out of new ideas plays in the advancement of science, our results buttress the case for funding scientific work by young researchers but also provide a caution against unconditional idolatry of youth over experience.
\end{abstract}

\title{
Keywords
}

ideas; science; aging; collaboration; biomedical research

Interviewers: "Are there any threats to progress and technical change on the horizon that you think are particularly worrisome? [...]"

Paul Romer: "I have one small concern. In general I'm very optimistic; despite political opposition and resistance to change and special interest groups, we've still had this process of accelerating growth over time. One factor that does worry me a little is the demographic changes that we're going through. Young people, I think, tend to be more innovative, more willing to take risks, more willing to do things

\footnotetext{
*We thank seminar participants at the UC-Berkeley Innovation Seminar, Aalto University, University at Buffalo, Kansas University, Boston University, Stanford Medical School, Google, the Diffusion of Innovations Group at the National Institutes of Health, and Innovation in an Aging Society working group for helpful comments. We also thank Tom Deleire, Joel Blit, Jeremy GoldhaberFiebert, Mike Hoy, Nico Lacetera, Grant Miller, David Studdert and Doug Owens for helpful conversations.

JEL Classification: I1, J11, O31, O32, O33
} 
differently, and they may be important, disproportionately important in this innovation and growth process. [...]"(pp. 106-7 in Kling and Schultz, 2009).

\section{INTRODUCTION}

Paul Romer - a prominent growth economist - sees one issue above others when thinking about threats to economic progress: the aging of scientists and inventors. The greying of the scientific workforce is a potential threat for at least two reasons. First, if older researchers tend to pursue more conventional research paths, the demographic shift may render science more stagnant and slow down economic progress. Second, when the demographic shift is coupled with a shift of power, control, and opportunities in academia toward older scholars it can become increasingly difficult for young scholars to pursue novel ideas. This too poses a threat to the vibrancy of science and economic growth.

The crux of this argument is the hypothesis that young and older researchers work in different ways. But what does it mean for two scientists to work differently? One key distinction is the vintage of the ideas on which a scientist builds; some build on recent ideas, while others build on well-established ones. There are a priori reasons to think that earlystage scientists are more inclined to try out new ideas as inputs to their own work (Samuelson, 1946; Holton, 1988). Eminent scientists, such as Charles Darwin and Max Planck thought that older scientists in their fields were especially unreceptive to their groundbreaking ideas because the minds of older scholars were not as flexible as are the minds of young scholars (Darwin, 1859; Planck, 1936; Rappa and Debackere, 1993). Modern authors have gone further, proposing that either cognitive decline that comes with aging, or the hardening of experience that comes with age, has a direct negative impact on creative capabilities (e.g. Butterfield, 1957; Galenson and Weinberg, 2000; Dietrich and Srinivasan, 2007).

There are other potential reasons as well. For instance, scientists closer to graduate school and post-doctoral training are more likely to be exposed to recent advances. By contrast, older scientists may simply have weaker incentives to learn new ideas (Diamond, 1980; Diamond, 1988). Older scientists have also vested interests - intellectual, social, and financial - that may render them less receptive to new ideas (Cohen, 1985). Moreover, senior scientists often have additional demands on their time in the form of committee work, review requests, advising, and other activities, which may limit their willingness to pursue time-intensive work that builds on recent and often still poorly understood advances. Some authors have suggested that young scientists might adopt new ideas more often merely because they do not know how unlikely new ideas are to result in success. James Watson went as far as to suggest that knowing too much "kills" you as a scientist (Rappa and Debackere, 1993).

Another possibility is selection; researchers who are willing to try out new ideas in their work may find it more difficult to stay in academia because novel work may be harder to publish and get funded compared to more conventional work (Kim, 2003). Thus, selection effects alone can produce a link between age and the vintage of idea inputs in a crosssection, even if each researcher stays true to the same research style throughout a career. For 
instance, Galenson (2012) notes several case-studies that suggest that scientists are like artists in that they are either conceptual or experimental innovators, a status that persists throughout one's career.

Conversely, there are also a priori reasons why later-career scientists might be more likely to try out new ideas. For instance, if a scientist is tenured, then the career harm from a failed project - more likely when trying out a new idea - is lower (Edge and Mulkay, 1976). Latercareer scientists may also want to avoid a stagnating part of the literature, and may try out new ideas to avoid this problem. There is thus no shortage of economic and biological theories concerning the link - in both directions - between age and the tendency of scientists to build on new ideas. Accordingly, it is ultimately an empirical question whether early-stage scientists are actually more likely to try out novel ideas compared to more seasoned scholars.

In this paper, we provide the first systematic large-scale investigation of the link between scientist age and the vintage of ideas that scientists use in their work. Specifically, we examine whether biomedical scientists who are early in their career are more or less likely to try out new ideas in their published papers than those who are later in their career. While our focus is on uncovering this link rather than the mechanisms behind it, our results also reveal some of the mechanisms to be more likely to be operational than others. Because teamwork is such an important part of the production of scientific work, as a secondary aim, we examine the link between the career-stage composition of research teams and the probability of that the work by the team builds on new ideas.

We focus on biomedicine because it is an important area of science and because of the availability of a large database of virtually all journal publications dating to the mid-1940s. Moreover, much of the debate on the aging of the scientific workforce has centered on biomedicine (e.g. Rockey, 2012; Daniels, 2015; National Institutes of Health, 2012). Rockey (2015) notes that between 1980 and 2014, the share of NIH funded principal investigators aged 35 and younger decreased from $21 \%$ to just $3 \%$ whereas the share of principal investors aged 66 and older increased from $1 \%$ to $7 \%$.

Our findings show that early-career scholars are much more likely to publish work that tries out new ideas than are late-career researchers. But our analysis of teams finds a positive role for experienced scientists as well: teams with a young first author and a mid-career last author are the most likely to try out new ideas. As the first author usually has the largest impact on a study (e.g. Zbar and Frank, 2011), our findings support the hypothesis that young scholars are key to innovative science. Yet, as the last author typically plays an important role as well - especially in terms of supervision, providing laboratory space, and acquiring funding (e.g. Zbar and Frank, 2011) - our findings suggest that a mix of experience on scientific teams may be important.

Despite the importance of the topic, the existing empirical evidence on the link between scientist age and the adoption of new ideas is restricted to small-scale studies on specific events; ours is the first to undertake a systematic and large-scale analysis of this phenomenon. The results from the existing literature are mixed. A study on evolution shows 
a statistically significant negative correlation between age and acceptance of the theory, supporting Darwin's contention that younger scientists were more likely to accept his ideas (Hull et al, 1978). A later re-analysis of the data finds the link to be small and statistically insignificant (Levin et al., 1995). In three studies on the adoption of new ideas in geology, one study finds support for the idea that older people are slower to adopt a new idea (plate tectonics) in their work (Nitecki et al, 1978), another study on the same idea finds that older scientists were actually quicker in adopting the idea in their work (Messeri, 1988), and a third study finds no link between age and the acceptance of a new idea (continental drift) (Stewart, 1986). A comparison of the age distribution of scientists who adopted a new idea (neural networks) in their work against the age distribution of all scientists finds an overrepresentation of young scientists in the former group (Rappa and Debackere, 1993). An analysis of the adoption of a new idea (cliometrics) in economic history finds that the link between age and adoption of the new idea to be negative but very weak (Diamond, 1980). An analysis of 28 high-profile scientific controversies from 1500s to 1900s finds a negative link between scientist age and the acceptance of new theories (Sulloway, 2014).

A separate but related strand of literature concerns the link between scientist age and research productivity as measured by the number of publications, journal rank, citations, grants, or prizes. The size of this literature dwarfs the size of the work on the age-vintage of idea inputs link. For example, a recent review by Jones et al. (2014) finds 26 studies on the age-scientific productivity link but just three studies on the age-idea adoption link, and one study (Weinberg 2006) that belongs to neither group. This focus on acts of genius in the literature has been convenient from an analytical point of view: it only requires counting publications, citations, and prizes. But from the perspective of the theory of science, this focus is wholly insufficient.

For as classic works on science and invention emphasize, one of the key ways that science advances is by the trying out of new ideas (Kuhn, 1962, 1977; Usher, 1929). While normal, non-transformative, science involves the incremental exploration of well-accepted ideas, novel ideas - in order to become transformative - also require careful and incremental elaboration by many scientists. Novel ideas, by their very nature, are poorly elaborated initially, and thus require much experimentation before the scientific community understands whether and where the new idea is likely to be useful at all. A scientific field is transformed by the trying out of a fruitful, novel idea (Kuhn, 1962, 1977; Usher, 1929). In more recent theoretical work Lucas (2008) forcefully rejects the emphasis on great men and their acts of genius, and instead sees economic progress largely as the result of the creative endeavors and exchange of ideas by literally millions of innovators rather than the result of rare acts of genius.

Transformative science thus requires considerable tolerance toward the testing of new ideas. This tolerance must extend beyond the scientist who came up with the new idea to other scientists in the field who are willing to lend their time and expertise to trying out the idea. A field advances when there is a critical mass of people who try out a new idea and, working both together and in parallel, find a way to make it fruitful. 
Consequently, uncovering the conditions that promote the trying out of new ideas is crucial for informed science policy. Uncovering these conditions is especially important in light of the disparity in attention between how age is linked to productivity as measured by publications, prizes or citations (which has been well researched) versus how age is linked to the tendency to try out of new ideas (which has not). Given the raw nature of initial insights and ideas in science, knowing the conditions under which researchers produce great insights is of little practical relevance unless one also knows the conditions that lead other researchers to further develop the great ideas when the ideas are still in their infancy.

The balance of the paper proceeds in the standard order: methods, results, discussion, and conclusion. Some of the more technical details of our approach as well as some sensitivity analyses are presented in the appendix.

\section{METHODS}

Our strategy is to analyze all published articles in the biomedical literature. For each publication, we first determine the age of the ideas that the article built upon and the career stage of each author. We then compare the ages of idea inputs across publications to measure how the career stage of the author(s) influences the tendency to build on new ideas. In this section we list the data sources and then present our approach.

\subsection{Data Sources}

2.1.1 Main Data Source: MEDLINE-Our main data source is the MEDLINE database. MEDLINE is U.S. National Library of Medicine's indexed database on over 20 million published biomedical journal articles. MEDLINE mainly covers nearly all biomedical research articles published 1946 to present day, but some older papers are also included. The database lists the title, authors, and journal of each article and also the abstract for articles published since 1975. We use the data available for download in November 2012, which cover years 1946-2011.

2.1.2 An Author Disambiguation Data Source: Author-ity-Our secondary data source is the "Author-ity" MEDLINE author disambiguation database (Torvik and Smalheiser, 2009; Torvik et al., 2005). This data source allows us to resolve the identity of scientists with the same name, even in years before unique author ids were assigned. We use the 2008 version of this disambiguation database. As a robustness check, we confirm the results using a simpler disambiguation approach that limits the analysis to authors with an unusual last name and initials combination.

\subsubsection{Research Areas Data Source: Medical Subject Headings Vocabulary-To} define research areas, we employ the Medical Subject Headings ("MESH") controlled vocabulary of over 20,000 terms. When papers are added to the MEDLINE database, professional indexers with a biomedical degree tag each paper with appropriate terms from the MESH vocabulary. We use these MESH terms to perform analyses in which papers are only compared to others papers published in the same research area; for these analyses we select MESH terms to serve as proxies for research areas. For instance, papers that are 
tagged with the same MESH disease term are likely related to the development of treatments to the same disease.

\subsection{Determining Career Stage of Each Author}

We define the career stage of each researcher as the number of years that has passed since the author's first publication in MEDLINE. While we do not determine the physical age of a researcher, we can accurately determine the career-stage of each author for articles published during 1980-2008. Others have suggested that career age is a more important driver of research productivity than physical age (Simonton, 1997). ${ }^{1}$

\subsection{Determining the Age of Idea Inputs}

We determine the ideas upon which a publication is built from the available text of the publication (title and abstract). By design, this text reveals the ideas that are central to the publication. While some of these ideas are brand new, most are ideas that the research that led to the publication built upon and recombined in a new way. To extract the idea inputs for a given publication, we construct a list of all words and 2- and 3-word sequences that appear in it (for example, cimetidine or nitric oxide synthase). For each idea that appears in any of the publications in the MEDLINE database, we determine the year that in which the idea is first mentioned in the database. ${ }^{2}, 3$ We refer to this year of first appearance as the "cohort" year of the idea, which corresponds to its vintage in subsequent years. Specifically, we measure the age of an idea input that is mentioned in a given publication by the years elapsed since the cohort year of the idea. For each publication, this approach yields both a list of the idea inputs that appear in it as well the vintage of each idea.

To show that this approach does indeed identify meaningful research inputs, we present a list of popular ideas identified by this approach as Table S1 in the appendix. This list is dominated by ideas that are easily recognized as having been important building blocks for biomedical research in recent decades. The list includes new methodologies (e.g. polymerase chain reaction), new pathologies (e.g. HIV), new molecules (e.g. caspase-3), new interpretations about causes for pathology (e.g. h. pylori), new biological pathways (e.g. small interfering $R N A s$ ), and advances in physical chemistry applied to biology (e.g. b3lyp), among many other categories of new ideas.

We address the possibility that the differential use of synonyms or buzzwords by young scientists might drive the results in two ways. First, we manually investigate the list of

\footnotetext{
${ }_{1}$ Measuring career age based on years elapsed since first publication introduces some measurement error that may be correlated with the dependent variable (age of idea inputs) because it may take less time to publish an innovative paper. However, we expect that in the era that we consider the magnitude of this measurement error is typically no more than several years whereas our analysis focuses on comparisons of career ages that are decades apart. It thus seems unlikely that this measurement error would drive our results.

2 Just because a new idea is found first in a paper in our database does not necessarily mean that the idea originated with the author(s) of the paper. It is possible that the idea originated outside biomedicine, for instance, and is not indexed in the MEDLINE data. At best we can infer that the authors are trying out that idea, which of course is the focus of our paper. As a robustness check, we perform the analyses also when idea mentions are ignored for the first year that the idea appears in the database.

${ }^{3}$ This approach has been applied to patents to uncover idea inputs in technological innovation (Packalen and Bhattacharya, 2012). Citations are an alternative approach to measure idea inputs (e.g. Jones et al, 2014) but are ill-suited for the present application. A citation to a recent publication does not necessarily indicate that a new idea is being tried out; it may reflect mere similarity of research goals rather than the trying out of an idea in the cited publication. Younger and older researchers have also different incentives to cite recent work, making comparisons of citation ages across authors at different career stages uninformative (Gingras et al, 2008).
} 
popular ideas inputs in each year and remove synonyms for old ideas. We conduct a sensitivity analysis with this edited list to test whether our main results change as a consequence. Second, if differential use of buzzwords are driving our results, we would expect groups of early-career scientists working alone - in the absence of more experienced scientists - to be the most likely to use newer words. We explicitly test whether this is the case.

Having obtained for each paper both a list of the idea inputs mentioned in it and a measure of the age of each of those ideas, we then determine the age of the newest idea input mentioned in it. This variable reveals whether each paper builds on any new ideas or only on more established knowledge.

Next, we rank all papers published in any given year based on the age of the newest idea input. We use this ranking to construct a variable that captures whether a paper builds on relatively recent ideas. Specifically, we construct an indicator variable that captures which publications are among the top $20 \%$ based on how recent is the newest idea input in each paper. This variable, denoted Top 20\% by Age of Idea Inputs, is our main outcome variable. ${ }^{4}$ In sensitivity analyses, we confirm that the results are robust to choosing a different cutoff percentile or a more restrictive comparison set than papers published in the same year.

For our primary results, we construct the idea input age measure for each paper based on mentions of the 100 ideas of each idea "cohort" that were mentioned the most often in publications by the end of the sample period (the cohort of an idea is the year that the idea first appears in the data). ${ }^{5}$ The focus on the top 100 ideas in each idea cohort centers attention on the early adoption of new ideas that turned out in retrospect to be used by many scientists. Arguably, it is most valuable to ascertain which author characteristics promote the trying out of the ideas that are the best (by the principle of revealed preference). But we also conduct sensitivity analyses based on mentions of the top 1,000 and the top 10,000 ideas in each idea cohort to test the extent to which our results extend to the trying out of new ideas in general, rather than just the most popular ideas.

\subsection{Sample Construction}

The author disambiguation data cover articles in MEDLINE through 2008. Because comprehensive MEDLINE coverage begins in 1946, career stage is much less accurately

\footnotetext{
${ }^{4} \mathrm{~A}$ formal representation of this outcome variable is as follows. Let $m i n M_{i, t}$ denote the age of the newest idea input for publication ( $i$, $t)$ published in year $t$. Denote by $M_{t}=\left\{\min M_{1, t}, \min M_{2, t}, \ldots, \min M_{N, t}\right\}$ a list that encompasses $\min M_{i, t}$ for all $N$ publications published in year $t$. Let \#\{ $\left.M_{t} \mid M_{t} \leq z\right\}$ be the number of elements in $M_{t}$ that are no larger than some constant $z$. Now define $\mathrm{F}(\mathrm{z})=$ $\mathrm{P}\left(\min _{i, t} \leq z\right)=\#\left\{M_{t} \mid M_{t} \leq z\right\} / N$ as the empirical cumulative density function, and define cutoff value $z 20_{t}$ such that $\mathrm{F}\left(z 20_{t} t\right)=0.20$. Our main outcome variable, Top 20\% by Age of Idea Inputs, is then constructed according to the formula

$$
\mathrm{d} 20_{i, t}=\left\{\begin{array}{l}
1 \text { if } \min M_{i, t} \leq z 20 \\
0 \text { otherwise }
\end{array} .\right.
$$
}

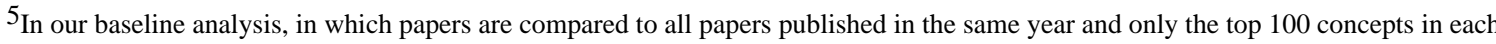
cohort are considered, the cutoff vintage for a paper to get the top 20\% status is 11 to 15 years (depending on the year of publication). That is, for all papers published during 1980-2008 any paper that mentioned a top 100 idea that was younger than 11 years at the time was designated the Top 20\% by Age of Idea Inputs status. The corresponding cutoff for the top 5\% status is 5 to 8 years depending on the year of publication. 
determined for articles published before 1980. We thus limit the analyses to articles published in years 1980-2008. The vintage of each idea input is, however, determined based on the text of all publications in MEDLINE.

While we determine (1) the cohort of a concept based on the year of its first appearance in any publication in the data, and (2) the rank of each concept within its cohort based on the number of times the concept appears in all the publications in the data, we limit the rest of the analysis to publications for which the available information on the title and abstract contains at least 30 words in total. For the excluded publications the data likely have too little information on their idea inputs.

We also restrict the analysis to regular journal articles, thereby excluding comments, editorials, case reports, etc. ${ }^{6}$ The rationale to limiting to regular journal articles is that older researchers are differentially more likely publish editorials and comments; including such articles in the analysis might bias the findings against older scholars.

We limit the analysis to career ages $0-40$ for two reasons. First, the comprehensive coverage of the data do not begin until 1946 and thus career ages older than 40 are not reliably determined for 1980s. Second, the lower number of research papers by researchers with career ages older than 40 implies that any obtained estimates involve considerably more uncertainty.

\subsection{Author-Article Level Analyses}

We conduct both parametric and non-parametric analyses. The non-parametric method is attractive because it generates visually striking graphs, but it does not permit a simple comparison across model results that pertain under different assumptions. To this end, we conduct our sensitivity analyses by estimating flexible parametric regression models instead.

In all analyses, both parametric and non-parametric, we weight observations so that the sum of the weights for articles published in any given year is the same as the sum of the weights for articles published any other year (1980 through 2008). Thus, we up-weight articles published in the earlier years as those years have fewer published articles. This way, the results are not driven by observations on the most recent years (the data contain more observations for the more recent years). In the parametric case we also report the estimates separately for each decade.

2.5.1 Non-Parametric Analyses-We start with non-parametric analyses, in which we determine for each career age 0 through 40 the share of papers that are innovative based on the dummy variable Top 20\% by Age of Idea Inputs. This captures the tendency of authors to build on new ideas at each career age.

\footnotetext{
${ }^{6}$ We achieve this by excluding articles that are not indexed with the MESH Publication Type term "Journal Article" and articles that are indexed with any of the MESH Publication Type terms "Review", "English Abstract", "Case Reports", "Historical Article" or "Comment", "Portrait" or have a MESH Publication Type term with any of the character sequences "biography", "Biography", "guideline", "Guideline", "News", or "Conference" in them (capturing multiple additional publication types that are not regular research articles).
} 
We start by analyzing each article-author pair in isolation. The focus on the first author is driven by evidence suggesting that in biomedicine the first author plays a key role in generating the ideas and doing the bulk of the work behind the paper (Shapiro et al., 1994; Baerlocher et al., 2007; Bhandari et al, 2004; Zbar and Frank, 2011). However, other authors too - especially the last author - also often contribute in those ways. Thus, we also examine the link between author age and age of idea inputs for all author-article pairs as well as for key author-article pairs, with the first and last authors of each papers considered as the two key authors.

\subsubsection{Parametric Analyses}

Our first set of parametric regression analyses examines the link at the author-article level using regressions where the outcome variable is the Top 20\% by Age of Idea Inputs dummy variable and the main explanatory variables are the following five dummy variables:

- $\quad \mathbf{d}($ Career Year 0), which is 1 for authors with career age 0 (the first year they publish a paper) and 0 otherwise.

- $\quad \mathbf{d}($ Career Year 1-10), which is 1 for authors with career age 1-10 and 0 otherwise.

- $\quad \mathbf{d}($ Career Year 11-20), which is 1 for authors with career age 11-20 and 0 otherwise.

- $\mathbf{d}($ Career Year 21-30), which is 1 for authors with career age 21-30 and 0 otherwise.

- $\quad \mathbf{d}($ Career Year 31-40), which is 1 for authors with career age 31-40 and 0 otherwise.

In reporting the results, we designate the last group d(Career Year 31-40) as the omitted group. In each estimation, the model involves also a set of fixed effects that varies across the analyses and is reported separately with the results. Denoting the dependent variable by $d 20_{j, t}$, where $t$ denotes year of publication and the tuple $(j, t)$ denotes a unique author-article instance of a paper published in year $t$, the regression equation can be written as

$$
\begin{array}{rl}
d 20_{j, t}=\beta_{0} & d(\text { Career Year } 0)_{j, t}+\beta_{1} d(\text { Career Year } 1-10)_{j, t} \\
& +\beta_{2} d(\text { Career Year } 11-20)_{j, t}+\beta_{3} d(\text { Career Year } 21-30)_{j, t}+\alpha_{t}+\varepsilon_{j, t},
\end{array}
$$

where coefficients $\beta_{0}$ through $\beta_{3}$ represent the parameters of interest, $a_{t}$ denotes year fixed effects and $\varepsilon_{j, t}$ denotes the error term. As in the non-parametric analyses, we start from analyses that only consider first author-article pairs but in robustness analyses extend the analysis to all author-article pairs as well as key author-article pairs. As the value of the outcome variable $d 20_{j, t}$ is calculated based on the characteristics of a research article, its value is the same for all author-article pairs that stem from the same research article.

In sensitivity analyses, we vary both the comparison group that is used to construct the dependent variable as well as the set of fixed effects that are included in the regression. For 
example, in one regression the comparison group is all other articles published in the same year in the same journal. The comparison group and fixed effects that are employed in each regression is reported with the results.

As discussed above, we also vary the set of concepts based on which the outcome variable is calculated from the top 100 concepts in each cohort to the top 1,000 and the top 10,000 concepts; when either of the latter concept sets is employed it is reported with the results. In addition, we employ alternative outcome variables, including the (1) raw age of the newest idea input in a paper, (2) an indicator variable capturing whether a paper is in the top 5\% newest based on the age of the newest idea input, and (3) an indicator variable capturing whether a paper is in the top 50\% newest based on the age of the newest idea input. When any of these alternative outcome variables is employed it is reported with the results.

\subsection{Team Characteristics-Article Level Analyses}

Having examined author-article pairs in isolation, we then extend the analysis to models that explicitly take into account the fact that the vast majority of biomedical science is a team activity (in the most recent years of our data, over $95 \%$ of original research papers had multiple authors). Again, we conduct both non-parametric and parametric analyses.

Using a non-parametric approach, we first determine how the share of papers with the Top $20 \%$ by Age of Idea Inputs status varies by the number of authors. We also calculate this fraction separately for each "career age of the first author, career age of the last author" combination. These analyses reveal the characteristics of teams with the highest and lowest tendencies to try out new ideas.

We also employ a parametric approach to examine how the career ages of the first and the last author relate to the propensity to try out new ideas. Specifically, we regress the outcome variable Top 20\% by Age of Idea Inputs on the following nine indicator variables:

- $\quad \mathbf{d}($ Young, Young), which is 1 if first and last authors both have career age 0-10 (and is 0 otherwise, obviously).

- $\quad \mathbf{d}($ Young, Middle), which is 1 if first author's career age is 0-10, last author's career age is $11-25$.

- $\quad \mathbf{d}($ Young, Old), which is 1 if first author's career age is 0-10, last author's career age is $26-40$.

- $\quad \mathbf{d}($ Middle, Young), which is 1 if first author's career age is 11-25, last author's career age is $0-10$.

- $\quad \mathbf{d}($ Middle, Middle), which is 1 if first author's career age is $11-25$, last author's career age is 11-25.

- $\quad \mathbf{d}$ (Middle, Old), which is 1 if first author's career age is 11-25, last author's career age is $26-40$.

- $\quad \mathbf{d}($ Old, Young), which is 1 if first author's career age is 26-40, last author's career age is $0-10$. 
- $\quad \mathbf{d}($ Old, Middle), which is 1 if first author's career age is $26-40$, last author's career age is $11-25$.

- $\quad \mathbf{d}($ Old, Old), which is 1 if first author's career age is 26-40, last author's career age is $26-40$.

In reporting the results, we designate the last group d(Old, Old) as the omitted group. Again, each estimated model includes a set of fixed effects that we vary in sensitivity analyses to examine robustness to different specifications. Results from these analyses show how the pairing of authors of different (or similar) career ages influences the propensity to try out new ideas.

Denoting by $t$ the year of publication and by using the tuple $(i, t)$ to uniquely identify each paper published in year $t$, the regression equation for these analyses can be formally written as

$$
\begin{array}{rl}
d 20_{i, t}=\beta_{0} & d(\text { Young, Young })_{i, t}+\beta_{1} d(\text { Young, Middle })_{i, t}+\beta_{2} d(\text { Young, } \text { Old })_{i, t} \\
& +\beta_{3} d(\text { Middle }, \text { Young })_{i, t}+\beta_{4} d(\text { Middle }, \text { Middle })_{i, t} \\
& +\beta_{5} d(\text { Middle, } \text { Old })_{i, t}+\beta_{6} d(\text { Old }, \text { Young })_{i, t}+\beta_{7} d(\text { Old }, \text { Middle })_{i, t} \\
& +\alpha_{t}+\varepsilon_{i, t},
\end{array}
$$

where coefficients $\beta_{0}$ through $\beta_{7}$ represent the parameters of interest, $a_{t}$ denotes year fixed effects and $\varepsilon_{j, t}$ denotes the error term. Parallel to the article-author level analyses, we conduct various robustness analyses (changing the fixed effects and how the dependent variable is calculated). We also conduct an additional set of analyses where the explanatory variables are constructed also based on the career stage of the second author.

\section{RESULTS}

We first show the results for author-article pair analyses; how the probability of referencing the most recently introduced ideas varies by the career age of the authors. Later in this section we show the results for the analyses that examine how teamwork and team composition affects the probability of trying out new ideas.

\subsection{Author-Article-Pair Analyses}

3.1.1 Non-Parametric Analyses-Figure 1 plots the relationship between author career age and the share of papers that built on new ideas. In the main panel, only the first authorarticle pairs are considered. The right panels of Figure 1 extend the analysis to all authorarticle pairs and to key author (first or last author)-article pairs.

Results in all three panels of Figure 1 support hypothesis that the propensity to try out new ideas is higher for early career researchers (career years 0-15) than it is for late-career researchers (career years 25-40). Also the magnitude of these differences is large: early career scientists are found to be 30-50\% more likely to try out new ideas than their most seasoned colleagues. Moreover, across all three approaches we find that the probability of 
trying out new ideas declines with career age after the early stage of a career. Because the results are consistent in this regard across the panels of Figure 1, we need take no strong position about which author contributed most. We should note that Figure 1 does not imply that only younger scientists try out novel ideas; according to the figure even late career scientists have a substantial, though significantly lesser, probability of trying out such ideas.

One finding that emerges from these results is that at the very start of a career - at career year 0 - the tendency to try out new idea is relatively low. One potential explanation for this finding is that researchers may feel pressure to first showcase their mastery of work that builds on more conventional ideas before allowing themselves to pursue more innovative research paths.

The results reported in Figure 1 were calculated based on all original research articles; both team and solo authored. The results for solo-authored papers alone are shown in Figure S1 in the appendix. For single-authored papers too, the probability of trying the most novel ideas declines with career age over the bulk of a career. However, solo authored papers as a whole - which form less than $4 \%$ of biomedical publications - are less likely to try out novel ideas than multi-authored papers. Furthermore, the probability of trying out novel ideas increases during the first ten to fifteen career years. One interpretation of this finding is that early career scientists need mentorship and support from others when they try out new ideas. We return to this issue below.

Results for coauthored papers are in turn reported in Figure S2 in the appendix. The decline in the propensity to try out of new ideas with career age of the first authors holds for coauthored papers as well. One possible explanation for this pattern may be that earlier career authors seek out more collaboration, resulting in papers with more novel ideas. We test this explanation by constructing the Top 20\% by Age of Idea Inputs variable only based on comparisons of papers published by the same number of authors in the same. The results are shown in panel B of Figure S2. We find that the decline in tolerance for novelty with career age persists when comparisons are only performed across papers with the same number of authors.

3.1.2 Parametric Regression Analyses-Parametric regression analyses that we conduct demonstrate that the results we show in Figure 1 are qualitatively and quantitatively robust to a wide variety of assumptions about the construction of the data, author disambiguation, years of analysis, the set of idea inputs that are considered, the way the novelty of idea inputs is calculated, and construction of comparison groups. Table 1 shows the first set of results that we obtain using estimating equation (1) in which the outcome is Top 20\% by Age of Idea Inputs. In all other columns except column 2, the comparison group for determining this top $20 \%$ status of an article is all other research articles published in the same year that have the same number of authors. ${ }^{7}$ In column 2 the comparison group is all other articles published in the same year. In each case the set of included fixed effects corresponds to the comparison group.

\footnotetext{
${ }^{7}$ This anticipates a finding shown in the next section according to which there's a link between the number of authors and the trying out of new ideas.
} 
Across the columns of Table 1 we mainly vary the set of authors considered. In columns 1-2 only the first author-article pairs are considered. In column 3 all author-article pairs are considered. In column 4 all key author-article pairs are considered. In column 5 only those first author-article pairs are considered for which the first and last authors are listed a nonalphabetical order. In column 6 only those first author-article pairs are considered for which all authors in the paper are listed the alphabetical order.

For each specification of Table 1, the estimated coefficient on the dummy variable d(Career Year 1-10) is positive, indicating that the propensity to try out new ideas is higher for early career researchers than researchers in the omitted group (late career researchers in career years 31-40). The coefficient on the dummy variable d(Career Year 1-10) is also higher than both the coefficient on the dummy variable d(Career Year 11-20) and the coefficient on the dummy variable d(Career Year 21-30). Thus, in every case, regardless of set of included author-article pairs, we find that that papers produced by authors with career age 110 are the most likely to reference newer ideas in their papers, authors with career age 11-20 are second most likely, authors in career age 21-30 third most likely, and authors with career age 31-40 least likely. While the exact differences between these groups vary by specification, qualitatively, this matches the results from the non-parametric analysis reported above (Figure 1). Hence, the finding that the propensity to try out new ideas is much higher for early career researchers than more seasoned researchers holds across the different sensitivity analyses reported in Table 1 .

Specifications reported in Tables 2-5 vary other aspects of the analyses, and each time again confirms the finding from the non-parametric analysis.

In Table 2 we show robustness to considering alternative author-name disambiguation approaches (columns 1-2), and to including author fixed effects (columns 3-6). ${ }^{8}$ In each case the results are qualitatively similar to the results shown in Table 1 . In the case of author fixed effects, the magnitude of the differences across career stages is smaller compared to the results shown in Table 1. One possible interpretation for such a combination of results that the difference is large without author fixed effects but is much smaller with author fixed effects - is that young researchers who build on novel ideas have a harder time sustaining their careers compared to their peers who pursue more established research paths. In the interview cited at the introduction Paul Romer suspected this to be true and that it would lead to younger researchers shying away from novel work.

In Table 3 we show robustness to having dependent variable be constructed based on the top $5 \%$ status as opposed to the top $20 \%$ status (column 1), having the dependent variable be raw age of idea inputs rather than the top $20 \%$ status (column 2), calculating the top $20 \%$ status based on the top 1,000 or the top 10,000 new ideas in each idea cohort rather than the top 100 ideas in each idea cohort (columns 3-4), excluding from the analysis those top 100

\footnotetext{
${ }^{8}$ The advantage of the second disambiguation approach is that it does not use information on research topics, unlike the Author-ity approach. In both columns 1-4 only first author-article pairs are considered. In column 5 all author-article pairs are considered. In column 6 only key author-article pairs are considered. In columns 5 and 6 the comparison group is articles published in the same year by the same number of authors. The "within-career" analyses presented in columns 3-6 form an exception to the rule on how the observations are weighted: for these analyses the observations are weighted so that the total weight of observations for any given author is the same as the total weight of observations for any other author.
} 
concepts which - based on a careful inspection of all concepts listed in Table S1 - might not represent genuine new idea inputs (column 5; excluded concepts are marked with the label "exclude for sensitivity analysis" in Table S1), excluding mentions of new ideas in the year in which they are first mentioned in the publications data (column 6), and only considering the first 50 mentions of each new idea (column 7). ${ }^{9}$ In each case the results are both qualitatively and quantitatively similar to our baseline results (Table 1). As we don't find a quantitative difference in the results when we consider the top 100 vs top 10,000 ideas in each cohort, the results indicate that young don't seem to have any better or worse judgement in terms of choosing which ideas to work (i.e. ideas that turn out to be the most useful vs. ideas that turn out to be less useful). Young just tend to work with new ideas in general more often than their more seasoned colleagues.

In Table 4 we show robustness of the baseline results to considering only each decade (1980s, 1990s, 2000s) at a time (columns 1-3), considering all journal articles as opposed to only original research articles in the analysis (columns 4-5), and to considering only those original research articles with a US first author as opposed to all original research articles (column 6). The time period for this last analysis is 1988-2008 as location information is mainly only available for articles published since 1988. In each case the results are both quantitatively and qualitatively similar to the results shown in Table 1.

In Table 5 we show robustness of the baseline results to comparing articles only to other articles published in the same year in same research area (columns 1-5) and to comparing articles only to other articles published in the same year in the same journal (column 6). ${ }^{10}$ Again, the results are qualitatively and quantitatively similar to the baseline results shown in Table 1. That is, in comparing two papers published in the same research field in the same year, one published by an earlier career first author is substantially more likely to try out newer ideas (in these analyses, research areas are determined from the MESH terms attached to each article), Similarly, in comparing two papers published in the same journal in the same year, the paper by an earlier career first author is more likely to try out newer ideas.

Thus, the various parametric analyses show that the findings from the non-parametric analyses are qualitatively and quantitatively quite robust. Of course, the age of an author need not be the only factor contributing to a propensity to try out new ideas. Other factors, such as team size and the career stage of collaborators may matter as well. We turn to these issues next.

\footnotetext{
${ }^{9}$ This last analysis of Table 3 (column 7) addresses the possibility that younger researchers 'jumping on a promising wagon' drive the results. Because in our baseline specification we calculate the age of idea inputs based on mentions of those new ideas that later become the most popular (top 100 of each cohort) idea inputs, our analysis centers on ideas that have stood the test of time rather than ideas that were quickly forgotten. In this additional analysis reported in column 7 of Table 3 , we show that our results are robust only considering the first 50 mentions of each such top 100 idea. Thus, bandwagon effects do not drive our results.

${ }^{10}$ In column 1 of Table 5 the comparison group for each article is all articles published in the same year that are indexed with the same MESH "Disease" terms (the C terms in MESH; only "major topic" terms are considered; we first truncate all MESH codes to 7 characters i.e. C11.294.177 becomes C11.294, and then require that all such 7 character codes are the same in two papers for them to be in the same comparison group). In column 2 the comparison groups are constructed based on MESH "Anatomy" terms. Thus, papers included in analyses reported in columns 1-2 represent applied biomedical research. Analyses reported in columns 3-5 in turn represent basic research; in these analyses we exclude papers that are indexed with any MESH "Disease" term. Furthermore, in these columns 3-5 the comparison groups are constructed based on MESH "Organisms", MESH "Chemicals and Drugs", and MESH "Phenomena and Processes" terms, respectively.
} 


\subsection{Team Size Analyses}

In Figure 2, we address the relationship between the number of authors on a paper and the likelihood of trying out the newest ideas. A priori, two distinct stories are possible. In one, each additional author may bring an additional chance for the project to consider a novel idea. Alternatively, group pressures may limit the willingness or incentives of individual scientists to advocate for new approaches (Olson, 1965; Donald et al., 1958). It is an empirical matter to check which story holds up best in the data.

Strikingly, each additional author increases the probability of referencing the newest ideas (Figure 2). Even adding a 9th or 10th author to a paper does not reduce this probability. These results are robust to adjusting for the ages of the key authors (Figure S3 in the appendix). It is possible to make too much of these findings - perhaps a project is more likely to attract middle authors if it successfully tries out the newest ideas. Nevertheless, it is clear that collaboration is not inherently destructive to the adoption of the newest ideas.

\subsection{Team Characteristics-Article Level Analyses}

In addition to the number of coauthors, the characteristics of the coauthors may matter as well. We are particularly interested in interactions that take place between the first author and last author of an article - stereotypically the authors who contribute most to the ideas in a biomedical research paper (Shapiro et al., 1994; Baerlocher et al., 2007; Bhandari et al, 2004; Zbar and Frank, 2011). Perhaps, to try out new ideas in a paper, there needs to be both a young scientist who is attuned to the novel ideas in the air, and a more experienced scientist who provides wisdom about whether the novel ideas are worth trying out. Alternatively, the presence of a late-career scientist on a project may discourage the use of the newest ideas.

In Figure 3 we present an analysis of how differing combinations of first author and last author experience contribute to trying out new ideas in a paper. The axes plot the career ages of the first and last author. We color each square of the grid according to the probability that the particular combination of author ages have of trying out new ideas (red is more likely, blue less).

The most striking finding in Figure 3 is that the career age of the first author plays the most important role in determining the tolerance for novelty. If the first author is in the first decade of his or her career, the chance of a paper trying out newer ideas is greatest nearly regardless of the career age of the last author (nearly all the dark and light red cells in Figure 3 are on the left side of the graph). Conversely, having a seasoned scientist as the last author does not prevent a high probability of trying out new ideas, as long as the first author is an early career scientist.

There are three important exceptions to the generalization that younger first authors are more likely to tolerate novelty. First, papers published by scientists who are at the very beginning of their career (left-most vertical line in the grid in Figure 3) are not as likely as other early career scientists to incorporate novelty - even if they are working with more senior scientists. This finding persists if we exclude authors with just one publication (Figure S4 in the appendix). 
Second, a team consisting of a young first author and a young last author (the bottom left of the grid in Figure 3) is less likely to try out novel ideas. For this team configuration, holding fixed the experience of the first author, papers are more likely to try out the newest ideas as the last author becomes more experienced.

Finally, if a young first author is paired with a very experienced senior author (the top left of the grid in Figure 3), the papers produced appear to be less likely to try out novel ideas than papers produced by a team with a mid-career senior author and a young lead author.

Parametric regression analyses conducted using equation (2) confirm that these patterns are robust to a variety of ways of constructing the sample, comparison groups, and unobserved control variables. The first set of these results are reported in Table 6. Unless otherwise noted, in the analyses the outcome variable is Top 20\% by Age of Idea Inputs, with idea inputs represented by the top 100 concepts in each cohort, and the comparison group is articles published in the same year by the same number of authors. In all cases the fixed effects correspond to the comparison groups based on which the outcome variable is constructed. In columns 1-2 we vary the set of articles considered. In column 1 all regular research articles are considered, whereas in column 2 only regular articles by authors located in the US are considered. In columns 3-4 we employ research area specific comparison groups. ${ }^{11}$ In column 5 the comparison group is articles published in the same year in the same journal. In column 6 we set Top 5\% by Age of Idea Inputs as the outcome variable. In column 7 we calculate the outcome variable based on the top 10,000 concepts in each cohort as opposed to the top 100 concepts in each cohort. Finally, in column 8 we employ an alternative author-name disambiguation.

Across the columns of Table 6, the coefficients on the dummy variables d(Young, Middle) and $\mathbf{d}$ (Young, Old) are positive, indicating that the propensity to try out new ideas is higher for teams with an early career first author and a mid- or a late-career last author than researchers in the omitted group (teams with late-career first and last authors). Moreover, the coefficient on the dummy variable d(Young, Middle) is higher than other any estimated coefficient and the coefficient on the dummy variable $\mathbf{d}(Y o u n g$, Old) is the second-highest of the estimated coefficients. This corresponds to the pattern reported above in the nonparametric analysis (Figure 3); the results thus confirm that younger authors working together with a more seasoned scholar is a setting in which the trying out of new ideas is most likely in biomedicine.

Further regression analyses consider the career ages of the first, last, and also the second author. That is, we augment the regression model (2) such that the dummy variables now also capture the career stage of the second author. The results are reported in Table S2 in the appendix. These results show that team combinations that are the most likely to try out new ideas again have a young first author and an experienced last author. The results also confirm that the first and last authors are the two key authors.

\footnotetext{
${ }^{11}$ In column 3 the comparison group is constructed based on MESH "Disease" terms and in column 4 the comparison group is constructed based on MESH "Phenomena and Processes" terms (similar to columns 1 and 5 of Table 5).
} 
One additional implication of Figure 3 (and the corresponding parametric results shown in Table 6) is that the novel terms used by young authors are not simply an idiosyncratic novelty due to relabeling of old ideas with new words. First, even when paired with older authors - who presumably know the standard terms when they exist - younger authors are more likely to try out the newest ideas. Second, when young first authors are paired with young last authors, they are less likely to try out new terms. Third, when we reanalyze our results using a list of popular novel ideas that have been manually edited to explicitly remove synonyms for old ideas, we find essentially the same pattern of results that we report in the figures above (column 6 of Table 6). Finally, the list of popular new ideas contains ideas that most knowledgeable experts would recognize as novel for their time rather than a repackaging of old ideas. It is thus unlikely that the appearance of the new terms reflects simply a preference for novel synonyms or buzzwords rather than the trying out of new ideas.

\section{DISCUSSION}

Our primary findings indicate that as biomedical scientists advance in age, they become less likely to publish papers that build on new ideas. This negative correlation between age and the likelihood of trying out newer ideas is mitigated when an older scientist works together with a young scientist - a combination that is more likely to try out newer ideas than a team consisting of only young scientists. These findings have important implications for science policy, suggest that some mechanisms are more likely to be operational than others, and complement the existing literature on scientific productivity.

\subsection{Implications for Science Policy}

The central problem in causal inference for our finding derives from the fact that we do not observe for any individual paper which author played the key role in including the novel idea in the research endeavor. How then should we interpret the negative correlation between author age and the propensity to try out new ideas? If it cannot be interpreted causally, does it still have an implication for policy? Here we suggest that the correlation itself has important implications for the organization of the scientific enterprise even if we cannot know which author - first or last - on an individual paper is the scientist who is the driving force behind its novelty.

To simplify matters, consider a paper that tries out a relatively new idea and has a mid-career last author and an early career first author. Consider first the case that it is the early career author who brought the novel idea input to the collaboration. This case supports a causal interpretation of the negative correlation between age and novelty; James Watson was right that "experience kills you as a scientist." The role of the senior scientist in this case is supportive and enabling one, providing the junior scientist with resources, feedback, guidance, or credibility without which it would have been difficult for the junior scientist to try out her idea in a meaningful way. The caveat here is that the mere power imbalance between the junior and the senior scientist (or simply the publishing norms of science) could result in the inclusion of the senior scientist on the author list. In a famous paper, Merton (1968) posited the Matthew effect in science, in which he argued that famous scientists gain 
more credit for an idea than do lesser known scientists who worked in parallel on the same idea. This gives an incentive for all teams to include a famous senior author on published papers: all else equal, including the senior scientist on the paper (as the last author) would bring more attention to the paper than would be the case if the senior scientist were not included. But this caveat does not change the central implication of this case: facilitating careers by young biomedical scientists leads to more innovative science.

Now consider the case that it the mid-career last author who is responsible for bringing the novel idea input to the collaboration. In this case, the power imbalance operates in the opposite direction. The fact that the junior author was included as the first author of the study almost by necessity implies that the junior author played some important role in bringing the paper to its fruition. There are several potential reasons for why a senior scientist who is eager to try a new idea would most often choose to collaborate with an early-career scientist. First, it may be that that these senior scientists view early-career scientists as being more willing to learn the new idea than their senior colleagues. Second, it may be they just need some collaborator and younger scholars are cheaper labor - either in terms of monetary costs or in terms of sharing scientific credit. Third, it may be that the midcareer last author wants to apply a novel technique that he/she does not yet completely master but which most recently minted graduates can apply. No matter which of these interpretations is correct, the fact that these mid-career last authors typically choose to work with young first authors when trying a new idea in their work implies - by revealed preference - that pursuing such work that tries out new ideas would become harder if there were less young collaborators around. Hence, from the perspective of encouraging innovative science it is important to support the careers of young biomedical scientists. In other words, when the graying of grant recipients makes it more difficult for young scientists to stay in academia, we may be making it more difficult for mid-career scientists to find suitable collaborators for the pursuit of innovative work that tries out new ideas.

The third and final case to consider is that the inclusion of the novel idea in the research paper is the result of collaboration between the junior and senior scientists that would not have happened in the absence of the collaboration. Obviously, this case also supports policies that encourage the education and development of junior scientists if the policy aim is to support innovative science.

Above we have argued that even though it is not known why young first authors are associated with innovative papers, our findings imply the graying of scientists and grant recipients will make the pursuit of innovative science more difficult. Yet, it is also important to keep in mind that our results indicate a positive role for experience as well, as it is the papers published by a team with a young first author and an experienced last author that try out new ideas the most often. Again, further research is needed to understand why this result arises: Do senior scientists have the idea? Or do they provide funding and guidance? Or does their name appear on papers merely to make the peer review process easier or to assist in the battle for scientific credit? Before we uncover the answers to these questions, our results on this dimension should serve as a reminder that academics and policy makers should take care not to go too far in their idolatry of youth over experience. 


\subsection{Implications for Theories on the Age-Novelty Link}

In addition to its implications for policy, the negative correlation we find between age and novelty suggests that some of the theoretical mechanisms posited in the science of science literature on scientist aging are more likely correct than others. For instance, our finding is consistent with the Diamond (1988) human capital model of scientist age and idea selection. (Though we could have chosen other theories to focus on here, we pick the Diamond model because it is in the human capital tradition, and is thus of particular interest to economists). Diamond models scientists' work effort as a choice between work on two sorts of theories: novel experimentation on a new theory (trying out new ideas in our nomenclature) and work on a conventional theory. In any given period, progress on a novel theory is assumed to increase linearly with the effort spent by a scientist. By contrast, progress on a more conventional theory is assumed to be proportional to both the effort spent this period and the discounted sum of effort spent by the scientist on that topic over a lifetime. Scientists who have spent time working on a conventional theory become much more efficient in producing contributions on that topic. Thus, the model implies that scientists optimally tend to favor work on novel theories when they are young because they have not yet built up the knowledge capital that would make them productive on conventional theories. As they get older, they build experience in conventional theory, and they switch away from their youthful work on novel theory instead. The correlation implied by this theory is exactly the correlation we find in our analysis of the biomedical literature. This does not mean that this particular theory is the only correct explanation. As we discuss in the introduction, there are other theories that are also consistent with our findings. But it does mean that the Diamond (1988) theory has survived this empirical challenge.

Similarly, our findings are consistent with Simonton's (1997) model of creativity and career age. In that model, scientists start their career with a fixed stock of ideas and capabilities; they accrue no new ideas over the course of their career. Rather, each scientist recombines those initial ideas and capacities in different ways over time to find those combinations that are most successful. In the model, it takes scientists some time to find the best combinations of ideas, but after that, there are diminishing returns. The model thus predicts that innovation rises initially with career stage, reaches a peak in mid-career, and then declines after that point. Our empirical findings are consistent with the premise of this model - that the willingness to try out new ideas peaks early in a scientist's career, though we find that also older scholars build on new ideas in their work albeit less often than their younger scientists.

Interestingly, our evidence is consistent with evidence from the literature on primatology. Kendal et al. (2005), for instance, conduct an experiment on Callitrichid monkeys, who are provided a novel way to collect resources. They find that the younger monkeys tend to be the first try out and play around with the novel mechanisms, but that older monkeys - attracted to the novelty by the interest of the younger monkeys - tend to be the ones that come up the solutions that allow the mechanism to be used most effectively. Perhaps younger human scientists are similarly naturally drawn to the trying out of new ideas more than are older human scientists. And perhaps the young human scientists too benefit from the presence of wiser older scientists that help them work through the many problems that we encounter when trying out new ideas that are raw and yet poorly understood. 
By contrast, our findings do not support theories that predict that scientists try out novel ideas more as they age. For example, our evidence in inconsistent with a theory that posits academic tenure enables scientists to take risks by trying out new ideas. It is still possible, of course, that tenure encourages novel exploration in science ceteris paribus, but that forces that run the opposite direction outweigh the tenure effect. We find it striking that - despite considerable effort - we have been unable to find a published paper that provides evidence for the role of tenure in encouraging novel exploration, which suggests perhaps that other researchers have been unable to corroborate it as well. At least it suggests that more serious work on the topic is warranted.

\subsection{Comparison with the Empirical Literature on Scientific Productivity}

As discussed in the introduction, the literature on scientific productivity focuses mostly on acts of genius, whereas our focus is on the trying out of new ideas. The main finding of this literature is that the age distribution of great achievements (as captured by prizes or highly cited publications) follows an inverted U-shape (e.g. Jones et al, 2014). Moreover, in most areas of science the tendency of these great achievements to come later in life has increased over the last century. In physics, chemistry, and medicine the mean age of at which Nobelprize winning discoveries are published is now (since 1985) 50 years, 46 years, and 45 years, respectively (Jones and Weinberg, 2011). Jones et al. (2014) conclude that because great achievements tend to come in the middle age, policies aimed at condensing training periods appear misguided.

In contrast with this literature, in which the focus is on measuring influence, our focus in this paper has been on whether research builds on relatively novel ideas. Our empirical results suggest that the propensity to try out new ideas may be declining over the whole life cycle. Of course, there is no contradiction between the existing literature and our findings: the propensity to try novel ideas may decline over a scientist's career, even as influence increases through the middle part of that same career. This difference suggests that supporting young scholars may have implications that are not captured by the literature on the age-acts of genius link. It thus appears valuable that future research on scientific productivity over the lifecycle examines both aspects of scientific papers - perceived influence and the vintage of idea inputs. We hope that our analysis and arguments nudge the literature toward this direction, and that our methods for measuring idea inputs and their vintage from research texts prove useful in facilitating such research.

\section{CONCLUSION}

When ideas are first born they are raw, poorly understood, and in need of revision and attention of many scientists (Kuhn, 1962, 1977; Usher, 1929). Scientific progress thus depends on scientists being willing to try out new ideas, and it is important to identify what conditions promote such scientific play. It is imperative that we understand, for example, whether the aging of the scientific workforce has the potential to pose the kind threat to the vibrancy of science and economic growth as is foreseen by the growth economist Paul Romer (see the introduction). 
We find that papers published by early-career scientists are (on average) more likely to try out newer ideas than papers published by late-career scientists. So perhaps Charles Darwin and Max Planck were right: younger scientists are more tolerant of novelty in their work. However, we do not believe that our results imply that, as Planck once wrote, science advances one obituary at a time. Instead, later-career scientists too appear to play an important role, implying that the abovementioned concerns about the aging of the scientific workforce are at least partly misplaced.

Specifically, we find that papers published by teams of younger scientists (as the first author) and mid-career or late-career scientists (as the last author), are more likely to reference newer ideas than are papers published teams consisting of only young scientists. Our results thus reinforce the importance of mentorship and teamwork in the adoption and trying out of new ideas in biomedical science. The stereotypical model of a successful scientific team envisions a brash, young scientist - brimming with untested insights - paired together with the wiser, older scientist with the judgment to help guide and encourage the young scientist. Our findings suggest that this model team is indeed fruitful for scientific progress, at least in terms of trying out and playing around with new ideas.

Since we do not directly observe the roles that the first and last author played in bringing an individual paper to fruition, we do not know why youth appears to be important to the trying out of new ideas. Implications are most straightforward when the young first author is the driving force behind the trying out of a new idea. But the implications persist also if it is actually the more seasoned last author who is the reason for why a project tries out a new idea. For the fact that those experienced last authors typically choose to collaborate with a young scholar (when working on an innovative project) implies - by revealed preference that if we make it more difficult for young scholars to stay in academia, the pursuit of innovative work becomes more difficult also for more seasoned scientists.

For funding agencies, our findings provide qualified support for giving a preference to early career-scientists. The National Institutes of Health (NIH) in the United States, for instance, explicitly gives early career scientists an advantage in their application for grant funding: early career applicants are not required to meet the same standards regarding past productivity in their evaluation by NIH scientific review panels. This policy is usually justified as an investment in the future - the NIH should be more willing to fund early career scientists who are less productive to date than older scientists as a way to help young scientists develop and mature. In this reasoning, there is a trade-off between funding highly productive grant applications now and less productive grant applications that will result in a better-trained scientific workforce in the future. Our findings suggest that a preference for early career scientists might have an additional benefit in terms of scientific productivity, by funding those scientists who are most likely to seek out novel ideas for their work.

The qualifications to this conclusion are two-fold. First, while we find that youth is important for the trying out of new ideas, we find that experience too plays a positive role. Hence, it is important that funding agencies and scholars do not go too far in their preference for youth without understanding first why innovative papers tend to have experienced last authors. Second, while youth seems to be an important driver of innovative science, we take 
no position here about the optimal level of novel (as opposed to conventional) science. Healthy science involves neither too little nor too much experimentation with new ideas; whether the marginal returns to investment in novel science are higher or lower than the marginal returns to investment in conventional science in a given scientific field at this point in time is a separate empirical question. In this regard our only contribution is our approach for identifying novel work from textual information - we hope that this approach can later be applied in a useful way to examine the practical benefits from different types of science.

Our findings do not necessarily extend beyond biomedicine. Because each scientific discipline is organized differently in terms of aspects such as teamwork, laboratory space, and mathematical complexity, the mechanisms that favor either youth or experience, or a mix of them, in one context need be as influential elsewhere. Another potential caveat arises due to increased life expectancy. As investments in health and human capital alike are endogenous to life expectancy (e.g. Ehrlich and Yin, 2014) the typical career trajectory of novelty may also change in response to changes expected career duration.

In terms of the literature on scientific productivity over the lifecycle, we hope that our analysis spurs a renewed interest on measuring what ideas scientists and inventors use as idea inputs. Such work will potentially be an important addition to this literature, which thus far has focused on measuring influence with a particular emphasis on acts of genius. For the driving force behind economic progress may well be the relentless creative tinkering done by millions of scientists and inventors rather than the rare acts of genius (Lucas, 2008). Understanding what characteristics determine which ideas scientists and inventors tinker with in their work may thus be one key input to designing policies that promote scientific and technological progress.

\section{Supplementary Material}

Refer to Web version on PubMed Central for supplementary material.

\section{Acknowledgments}

We acknowledge financial support from the National Institute on Aging grant P01-AG039347.

\section{References}

Baerlocher MO, Newton M, Gautam T, Tomlinson G, Detsky AS. 2007; The Meaning of Author Order in Medical Research. J Investig Med. 55(4):175-180.

Bhandari M, Busse JW, Kulkarni AV, Devereaux PJ, Leece P, Guyatt GH. 2004; Interpreting Authorship Order and Corresponding Authorship. Epidemiology. 15(1):125-6. [PubMed: 14712157]

Butterfield, H. The Origins of Modern Science. New York: Free Press; 1957. Revised Edition

Cohen, IB. Revolution in Science. Cambridge, Mass: Harvard University Press; 1985.

Daniels RJ. 2015; A Generation at risk: Young investigators and the future of the biomedical workforce. Proceedings of the National Academy of Sciences. 112(2):313-8.

Darwin, C. On the Origin of Species. London: John Murray, Albemarle Street; 1859.

Diamond AM Jr. 1980; Age and the Acceptance of Cliometrics. Journal of Economic History. 40(4): 838-841.

Diamond AM Jr. 1988; Science as a Rational Enterprise. Theory and Decision. 24:147-67. 
Dietrich A, Srinivasan N. 2007; The Optimal Age to Start a Revolution. Journal of Creative Behavior. 41(1):54-74.

Donald TW, Berry PC, Block CH. 1958; Does Group Participation When Using Brainstorming Facilitate or Inhibit Creative Thinking? Administrative Science Quarterly. 3(1):23-47.

Edge, DO, Mulkay, MJ. Astronomy Transformed: The Emergence of Radio Astronomy in Britain. New York: John Wiley \& Sons; 1976.

Ehrlich I, Yin Y. 2013; Equilibrium Health Spending and Population Aging in a Model of Endogenous Growth: Will the GDP Share of Health Spending Keep Rising? Journal of Human Capital. 7(4): 411-447.

Galenson DW, Weinberg BA. 2000; Age and the quality of work: the case of modern American painters. Journal of Political Economy. 108(4):761-777.

Galenson DW. 2012Understanding the Creativity of Scientists and Entrepreneurs. Mimeo.

Gingras Y, Larivie V, Macaluso B, Robitaille J-P. 2008; The Effects of Aging on Researchers' Publication and Citation Patterns. PLoS One. 3(12):e4048-12. 1-12. [PubMed: 19112502]

Holton, G. Thematic Origins of Scientific Thought: Kepler to Einstein. Cambridge, Mass: Harvard University Press; 1988.

Hull DL, Tessner PD, Diamond AM Jr. 1978; Planck’s principle. Science. 202:717-723. [PubMed: 17807228]

Jones, B, Reedy, EJ, Weinberg, BA. Age and Scientific Genius. In: Simonton, DK, editor. Handbook of Genius. Oxford, UK: Wiley; 2014. 422-450.

Jones B, Weinberg BA. 2011; Age and Dynamics of Scientific Creativity. Proceedings of the National Academy of Sciences. 108(47):18910-18914.

Kendal RL, Coe RL, Laland KN. 2005; Age Differences in Neophilia, Exploration, and Innovation in Family Groups of Callitrichid Monkeys. American Journal of Primatology. 66:167-188. [PubMed: 15940712]

Kim S. 2003; The impact of research productivity on early retirement of university professors. Industrial Relations. 42(1):106-125.

Kling, A, Schultz, N. From Poverty to Prosperity. Encounter Books; 2009.

Kuhn, TS. The Structure of Scientific Revolutions. Chicago: University of Chicago Press; 1962.

Kuhn, TS. Objectivity, Value Judgment and Theory Choice. In: Kuhn, TS, editor. The Essential Tension. Chicago: University of Chicago Press; 1977. 320-339.

Levin SG, Stephan PE, Walker AB. 1995; Planck’s Principle Revisited: A Note. Social Science Studies. 25(2):275-283.

Lucas RE Jr. 2008; Ideas and Growth. Economica. 76:1-19.

Merton RK. 1968; The Matthew effect in science. Science. 159(3810):56-63.

Messeri P. 1988; Age differences in the reception of new scientific theories: The case of plate tectonics. Social Studies of Science. 18(1):91-112.

National Institutes of Health. Biomedical Research Workforce Working Group Report. 2012. Available at: http://acd.od.nih.gov/biomedical_research_wgreport.pdf (last accessed: 10 April 2015).

Nitecki MH, Lemke JL, Pullman HW, Johnson ME. 1978; Acceptance of plate tectonic theory by geologists. Geology. 6:661-664.

Olson, M. The Logic of Collective Action. Cambridge, MA: Harvard University Press; 1965.

Packalen, M; Bhattacharya, J. Words in Patents: Research Inputs and the Value of Innovativeness in Invention. NBER Working Paper\#19484. 2012. Available at www.nber.org/papers/w18494

Planck, M. Philosophy of Physics. New York: WW. Norton \& Company; 1936.

Rappa M, Debackere K. 1993; Youth and scientific innovation: The role of young scientists in the development of a new field. Minerva. 31(1):1-20.

Rockey, S. Age Distribution of IH Principal Investigators and Medical School Faculty. 2012. Available at http://nexus.od.nih.gov/all/2012/02/13/age-distribution-of-nih-principal-investigators-andmedical-school-faculty/ (last accessed: 10 April 2015).

Rockey, S. More Data on Age and the Work Force. 2015. Available at https://nexus.od.nih.gov/all/ 2015/03/25/age-of-investigator/ (last accessed 5 May 2016). 
Samuelson PA. 1946; Lord Keynes and the General Theory. Econometrica. 14(3):187-200.

Shapiro DW, Wenger NS, Shapiro MF. 1994; The contributions of authors of multiauthored biomedical research papers. JAMA. 271(6):438-42. [PubMed: 8295318]

Simonton DK. 1997; Creative productivity: A predictive and explanatory model of career trajectories and landmark. Psychol Rev. 104(1):66-89.

Stewart JA. 1986; Drifting continents and colliding paradigms: A quantitative application of the interests perspective. Social Studies of Science. 16(2):261-279.

Sulloway, FJ. Openness to Scientific Genius. In: Simonton, DK, editor. Handbook of Genius. Oxford UK: Wiley; 2014. 546-563.

Torvik VI, Smalheiser NR. 2009; Author name disambiguation in MEDLINE. ACM Transactions on Knowledge Discovery from Data. 3(3):11:1-11:29. [PubMed: 20072710]

Torvik VI, Weeber M, Swanson DR, Smalheiser NR. 2005; A Probabilistic Similarity Metric for Medline Records: A Model for Author Name Disambiguation. Journal of the American Society for Information Science and Technology. 56(2):140-158.

Usher, AP. A History of Mechanical Inventions. New York: McGraw-Hill; 1929.

Weinberg, BA. Which labor economists invested in human capital?. Geography, vintage and participation in scientific revolutions. 2006. Available at economics.sbs.ohio-state.edu/weinberg/ hcrev.pdflast accessed 10/18/2014

Zbar A, Frank E. 2011; Significance of Authorship Position: An Open-Ended International Assessment. Am J Med Sci. 341(2):106-9. [PubMed: 20924283] 
(A) First Author-Article Pairs

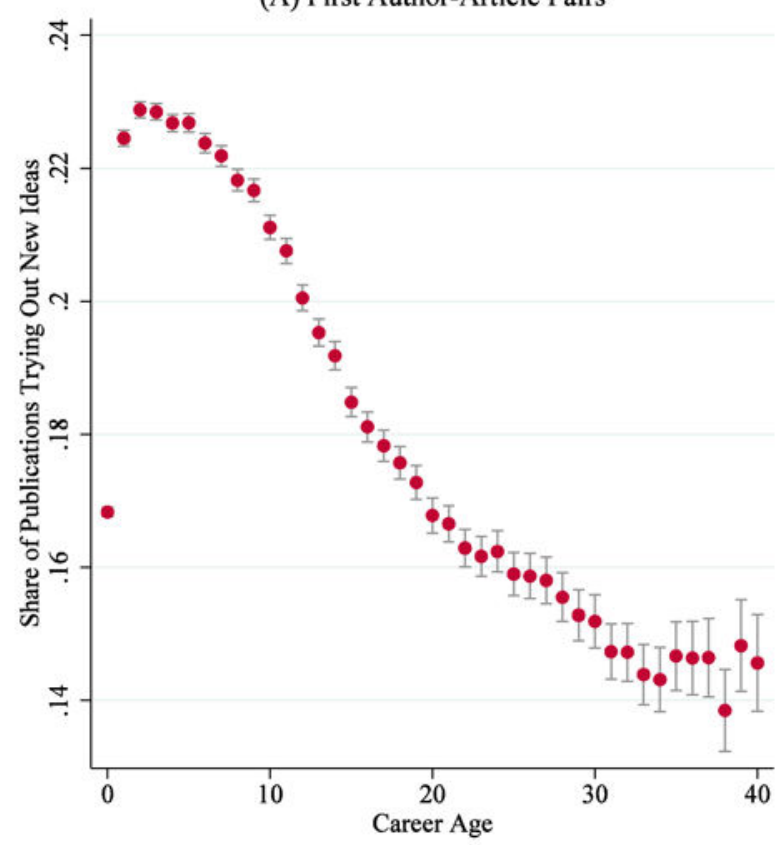

(B) All Author-Article Pairs
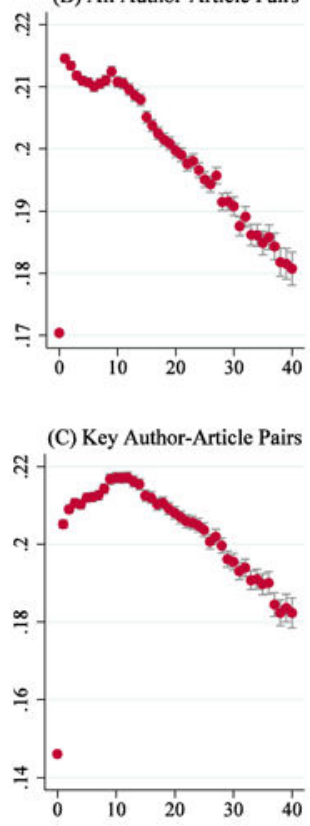

Figure 1.

Relationship between career age and the trying out of new ideas in all research articles (team and solo authored). Panels capture first author-article pairs (A; N=6,421,082); all authorarticle pairs ( $B ; N=28,808,579)$, and key author-article pairs ( $\mathrm{B} ; \mathrm{N}=12,205,850)$. In each panel, the vertical axis depicts the share of publications that are among the top $20 \%$ based on how recent is the newest idea input in each paper. The horizontal axis depicts the career age of an author. Capped lines indicate $95 \%$ confidence intervals. 
Team Size and the Trying Out of New Ideas

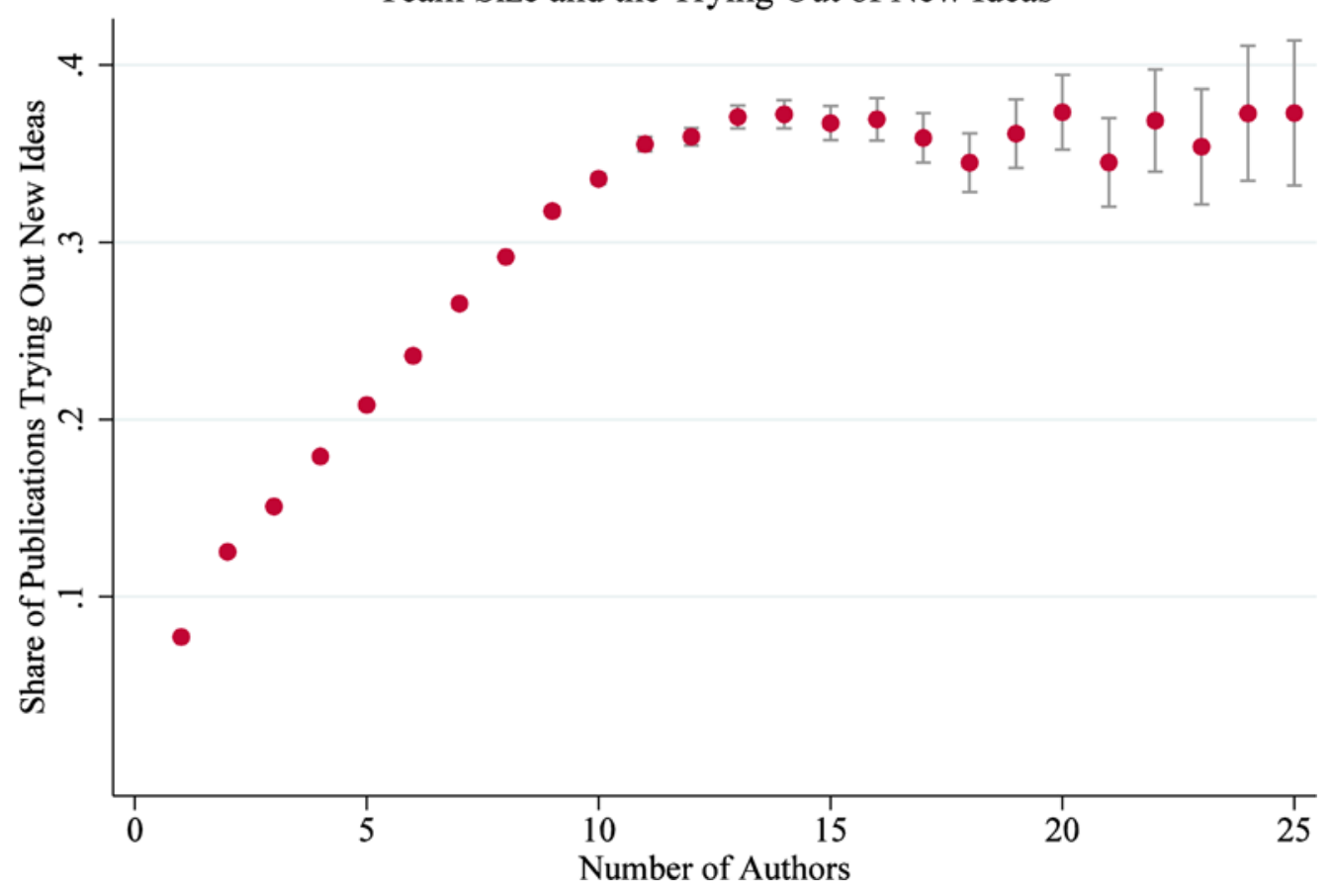

Figure 2.

Relationship between the number of authors and the trying out of new ideas $(\mathrm{N}=3,805,907)$. The vertical axis depicts the share of publications that are among the top $20 \%$ based on how recent is the newest idea input in each paper. The horizontal axis depicts the number of authors. Capped lines indicate $95 \%$ confidence intervals. 


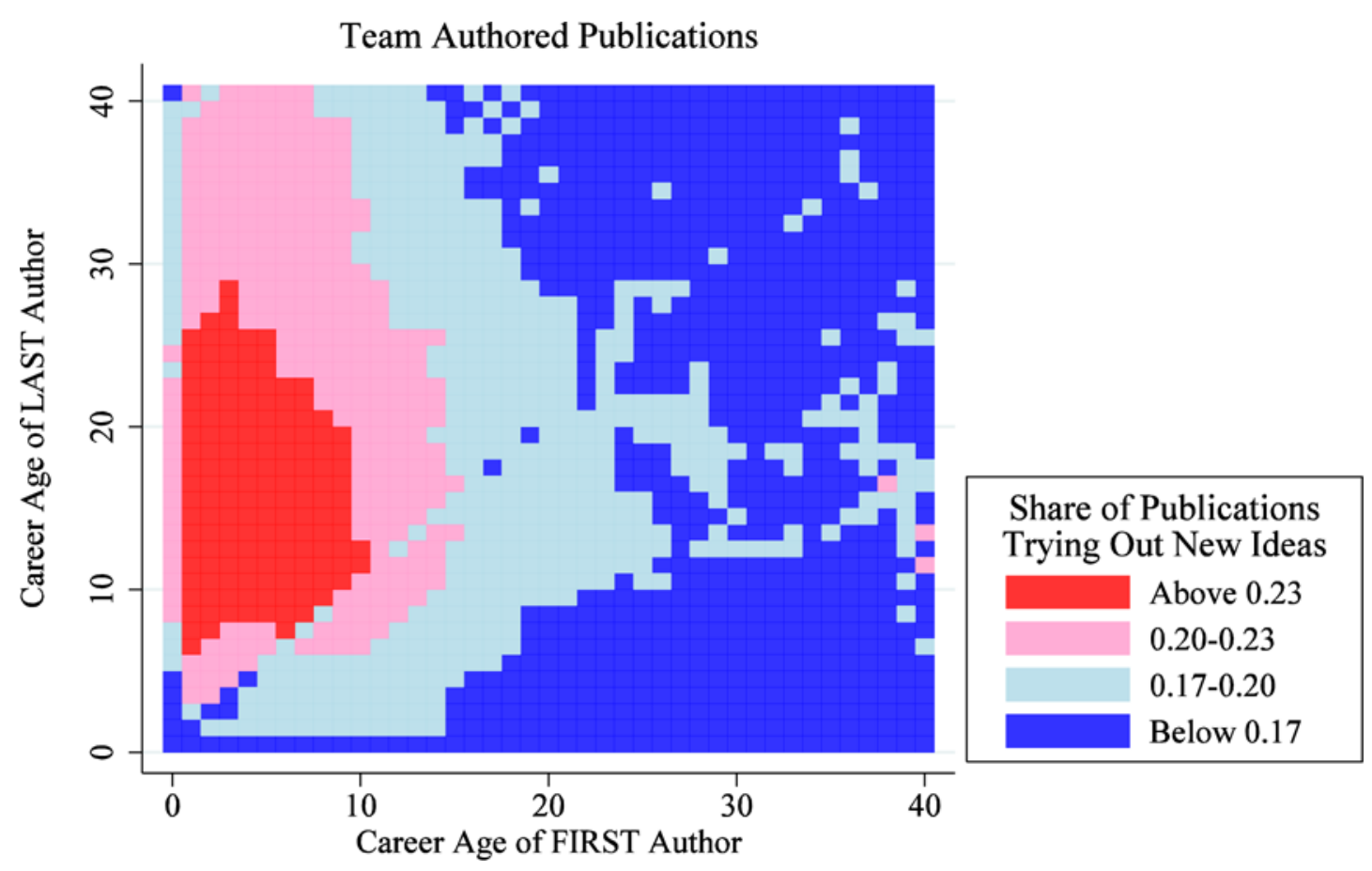

Figure 3.

Relationship between career ages and the trying out of new ideas among team authored publications $(\mathrm{N}=5,785,239)$. The vertical axis depicts the career age of the last author. The horizontal axis depicts the career age of the first author. Colors capture the share of publications that are among the top $20 \%$ based on how recent is the newest idea input in each paper. To calculate the top $20 \%$ status, each paper is compared to other papers that were published in the same year and have the same number of authors. 


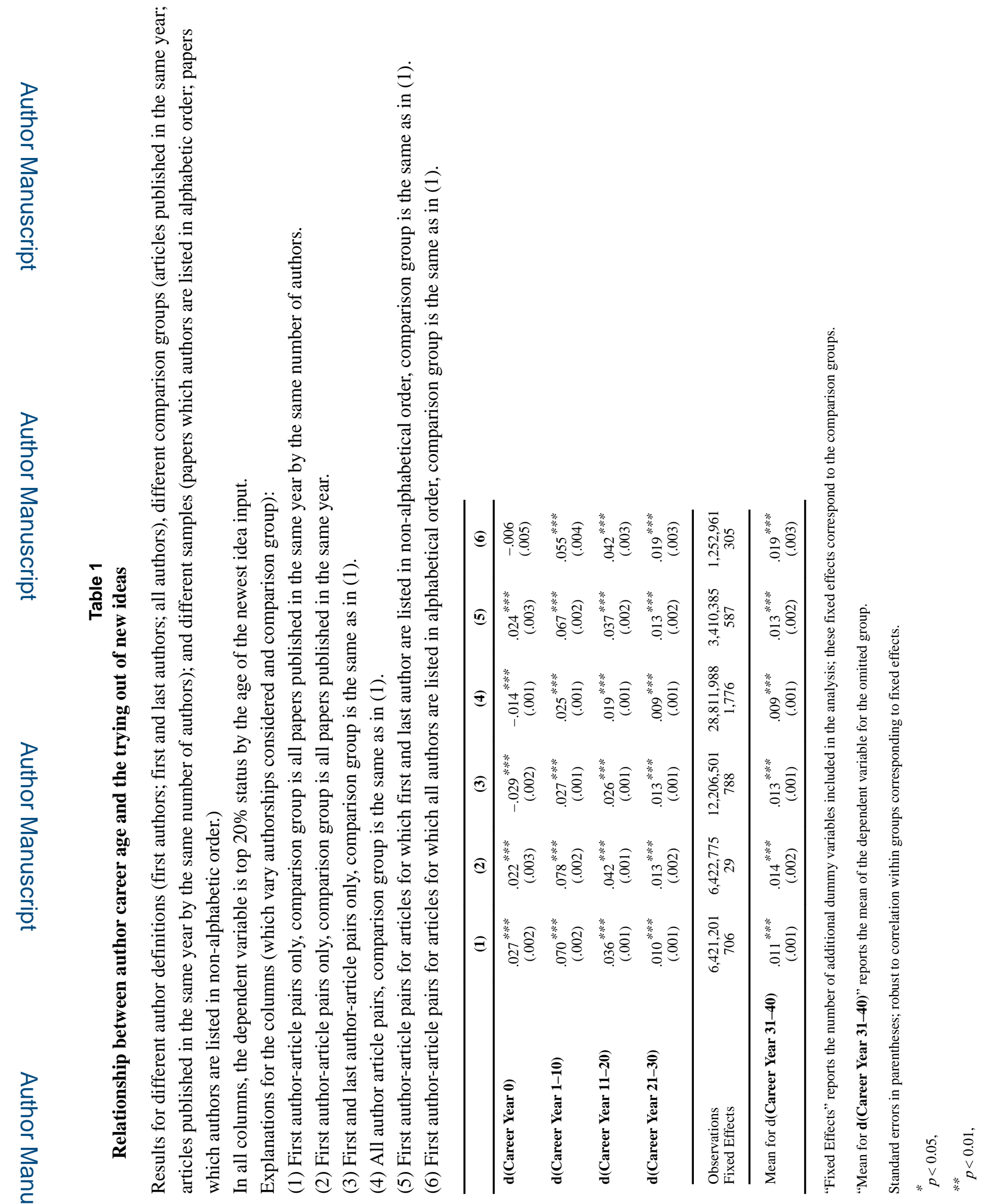

J Hum Cap. Author manuscript; available in PMC 2019 August 21. 


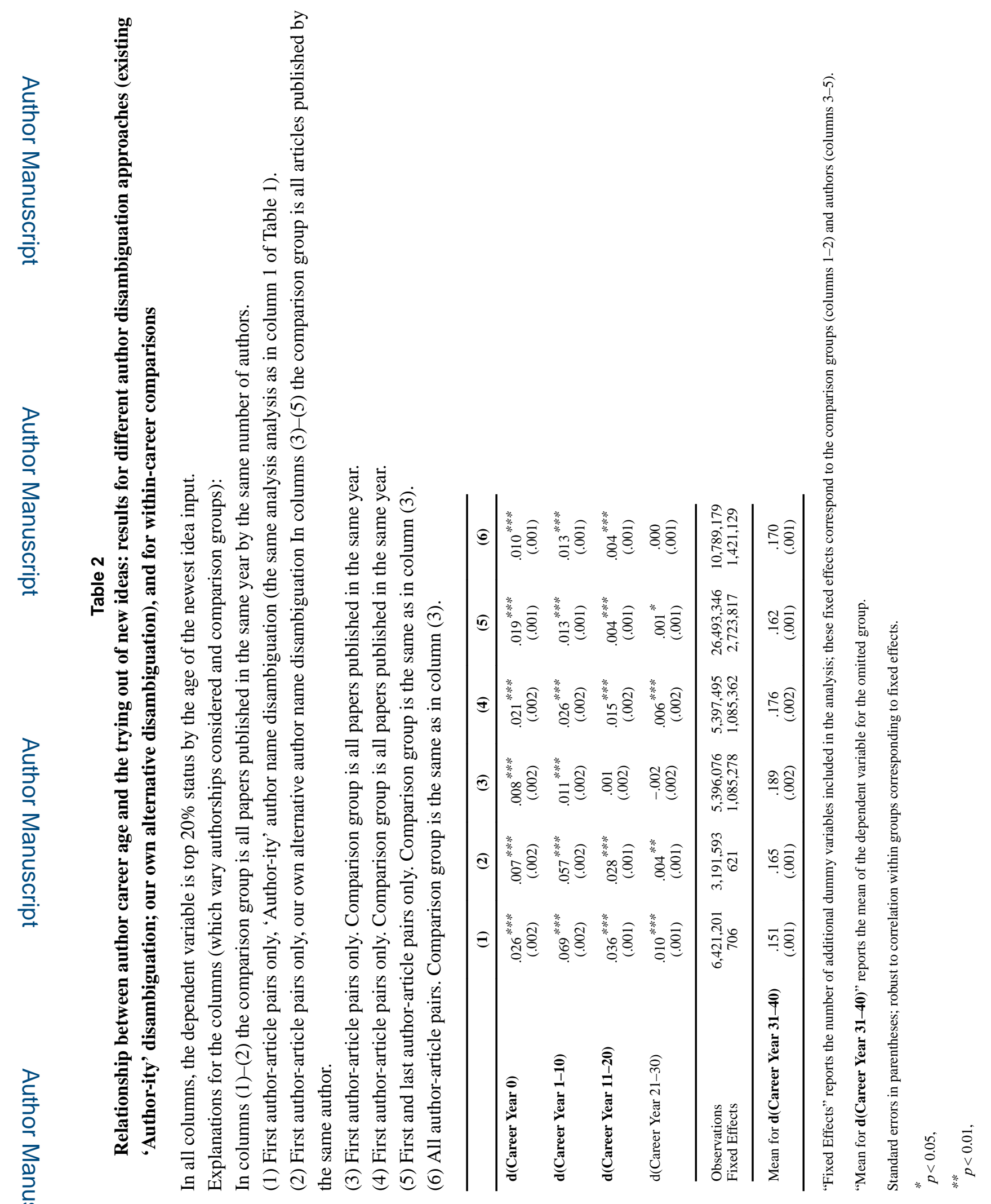

J Hum Cap. Author manuscript; available in PMC 2019 August 21. 


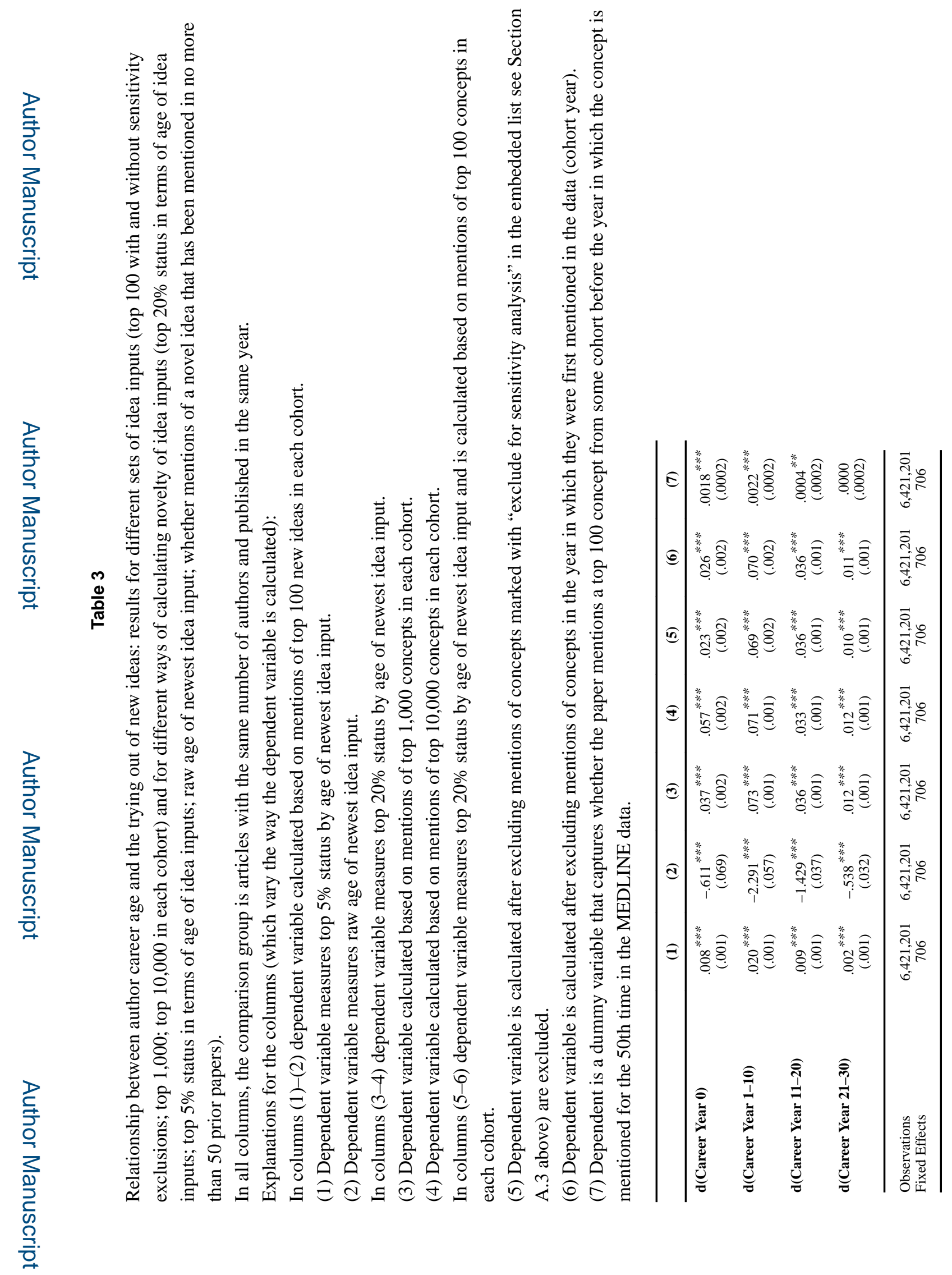

J Hum Cap. Author manuscript; available in PMC 2019 August 21. 


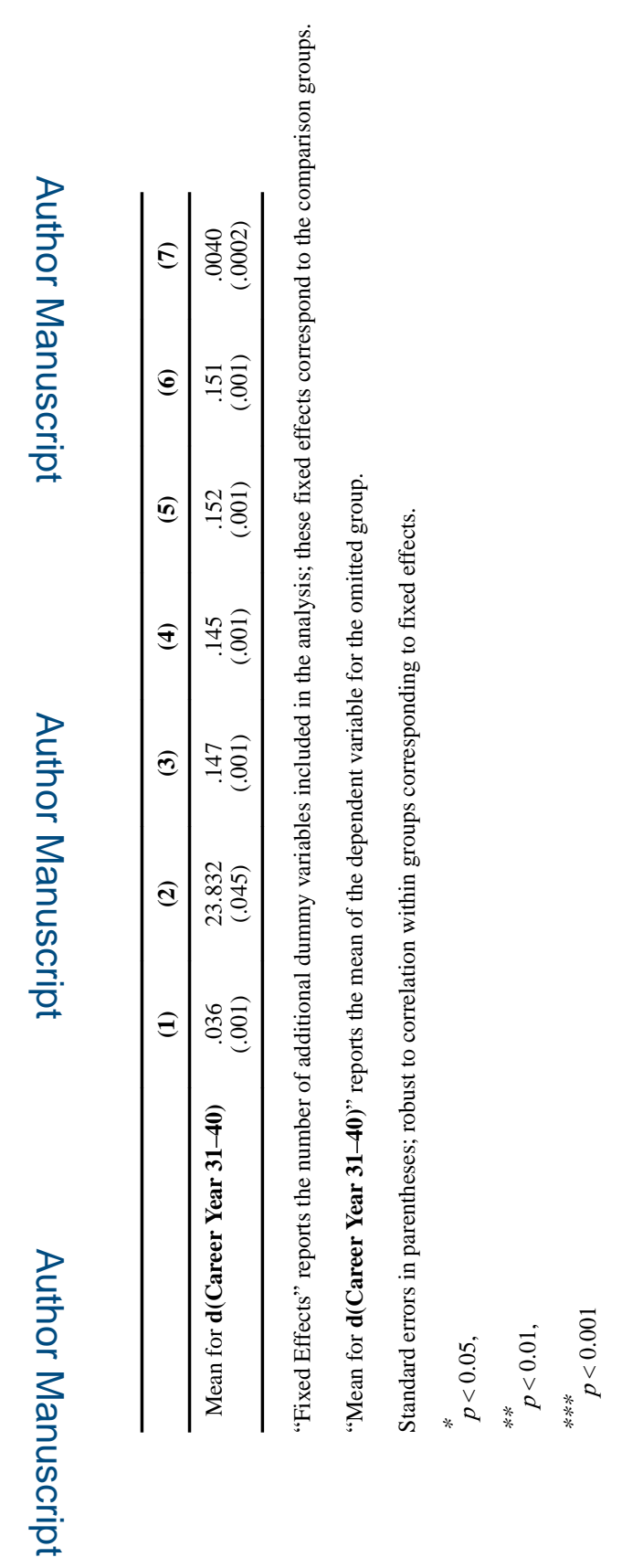




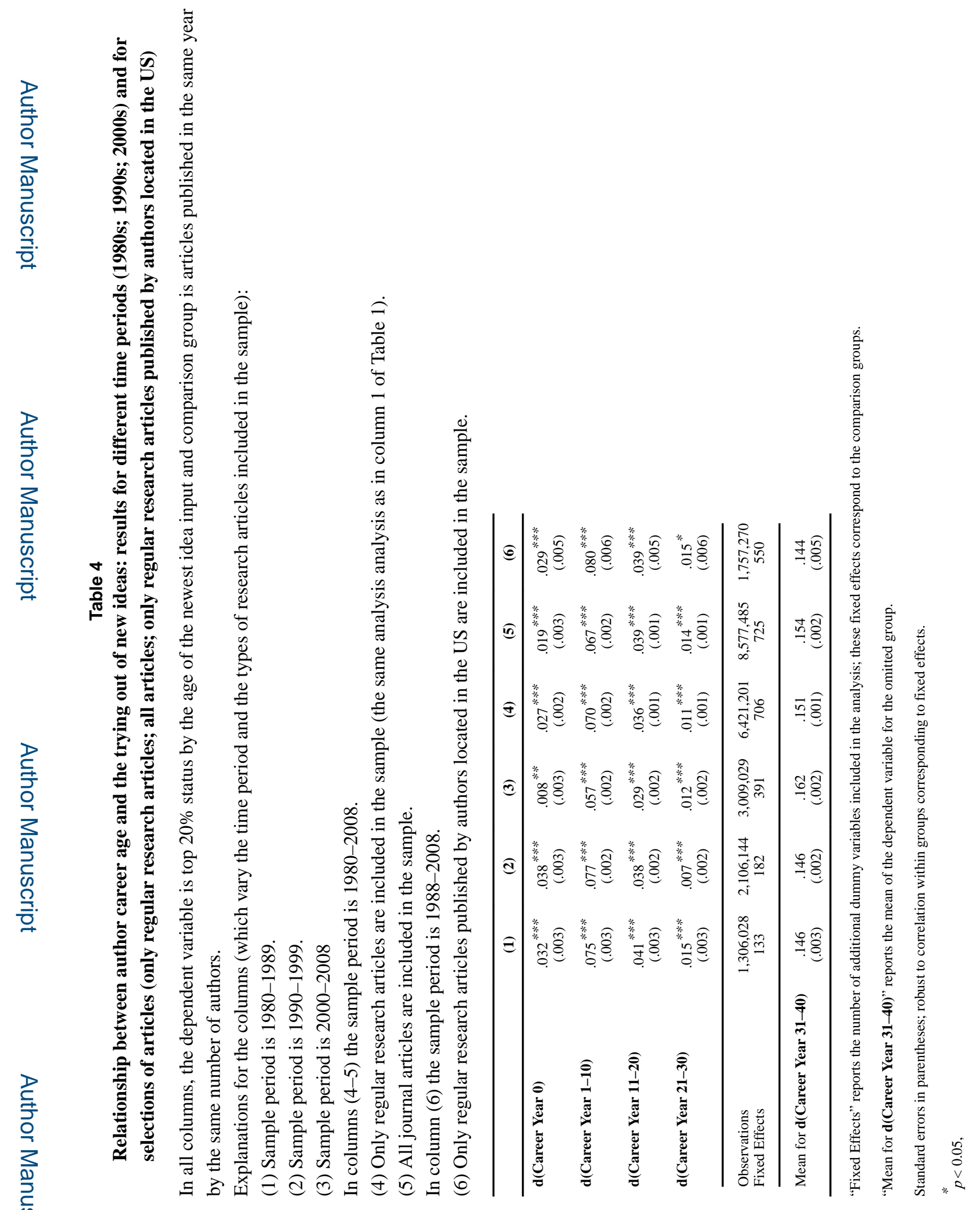

J Hum Cap. Author manuscript; available in PMC 2019 August 21. 

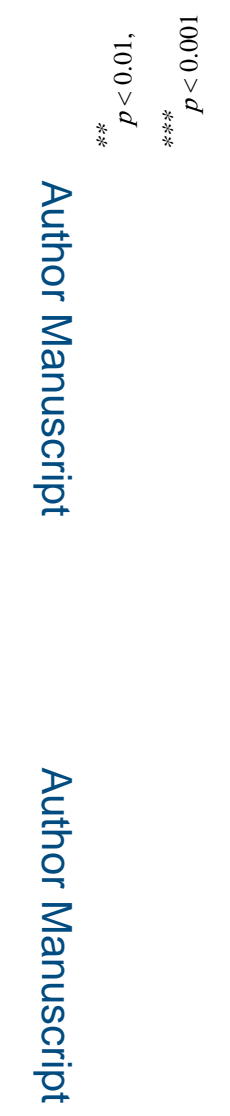

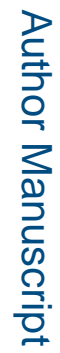

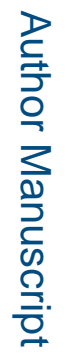

J Hum Cap. Author manuscript; available in PMC 2019 August 21. 


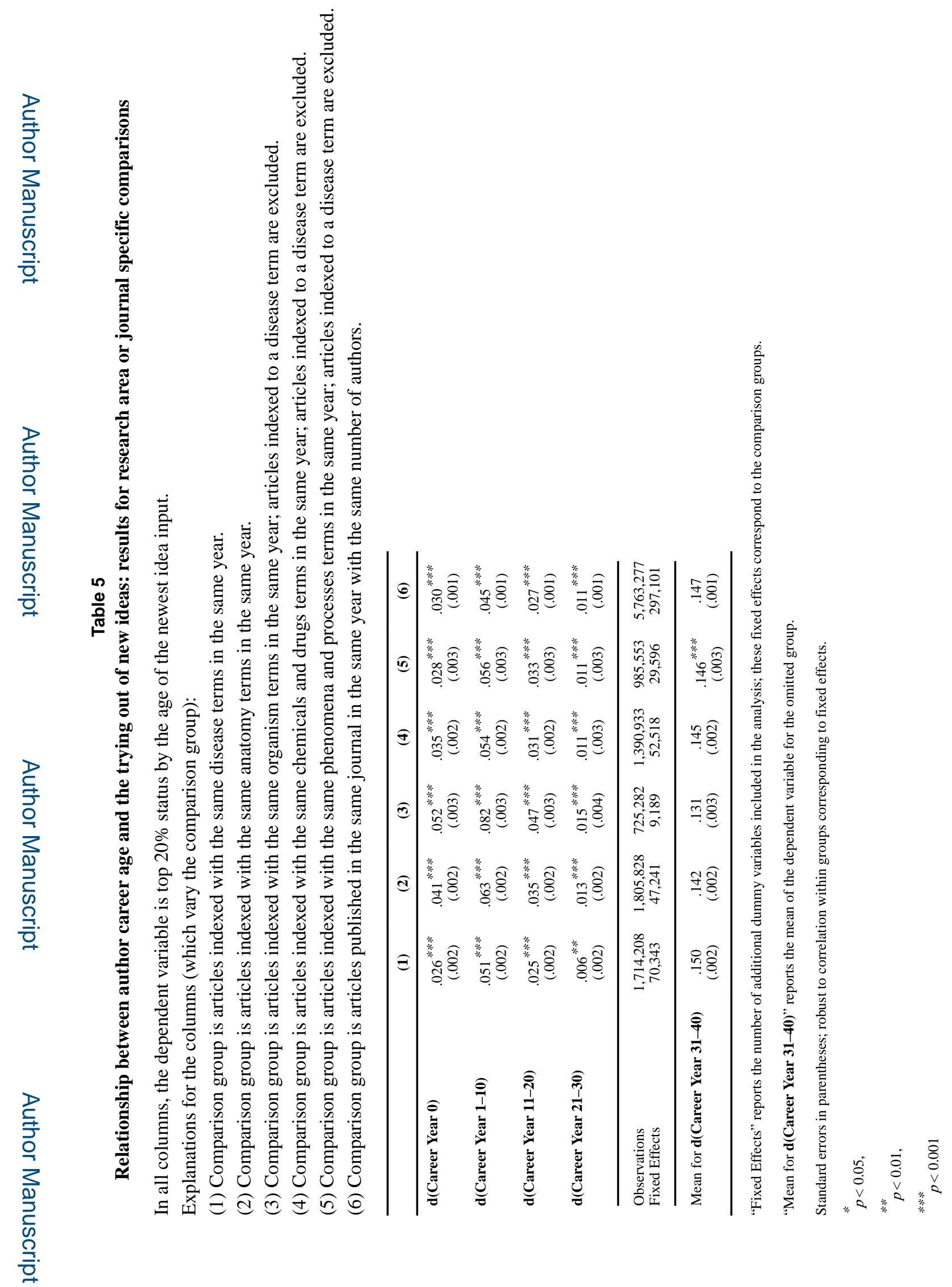

J Hum Cap. Author manuscript; available in PMC 2019 August 21. 


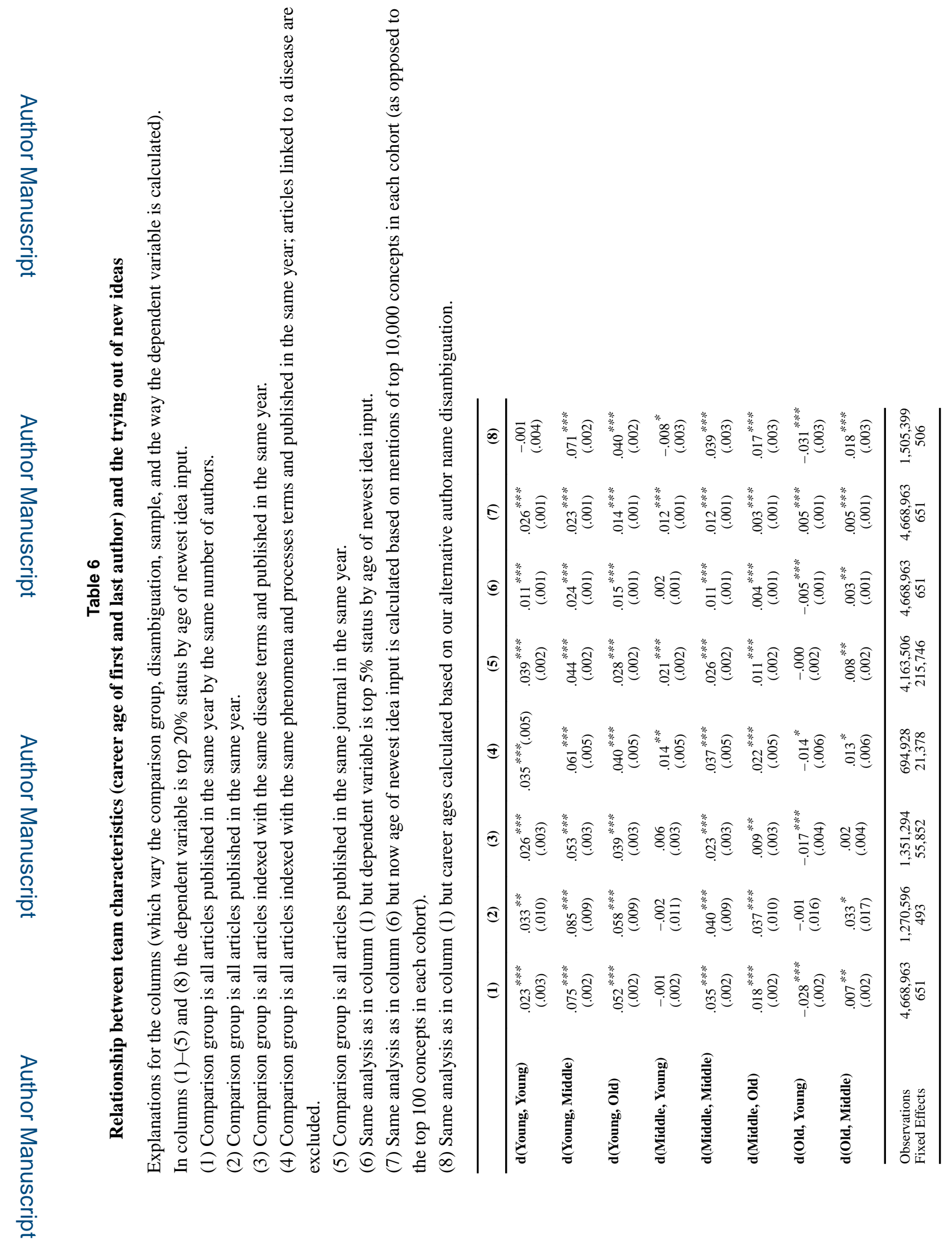

J Hum Cap. Author manuscript; available in PMC 2019 August 21. 


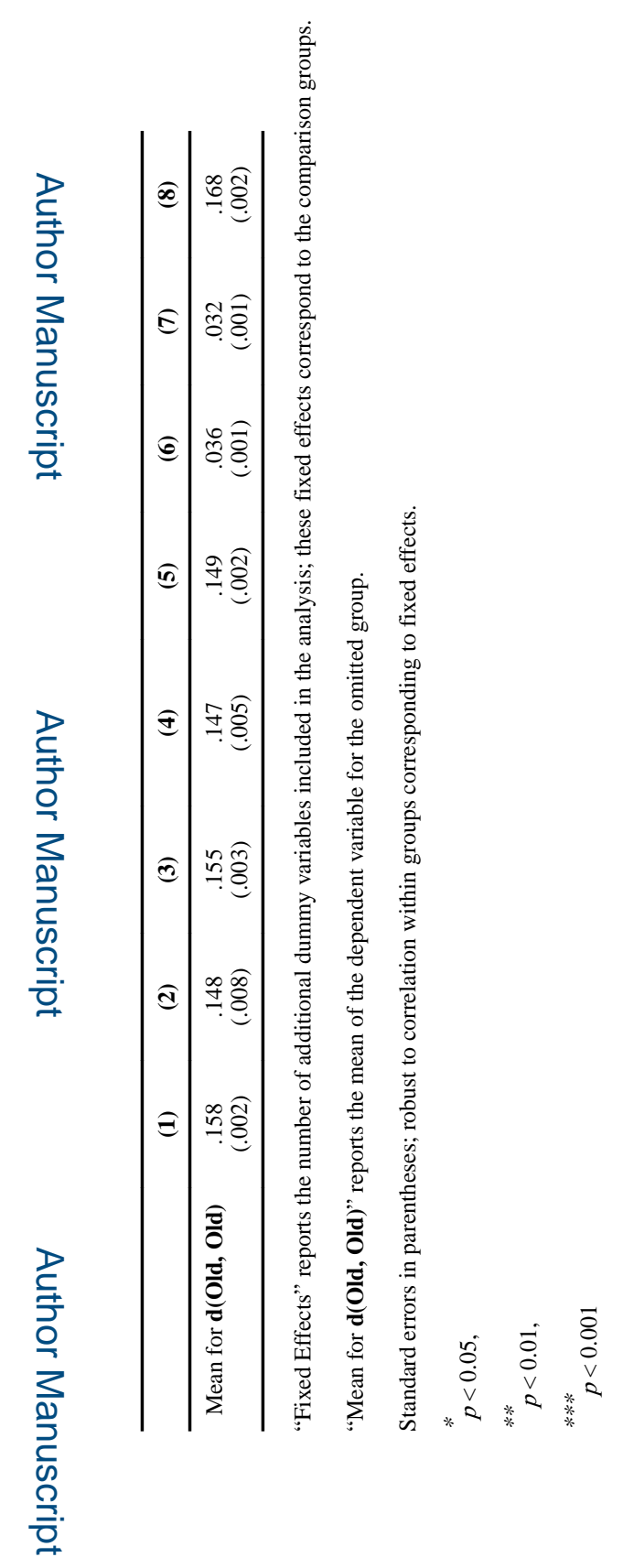

